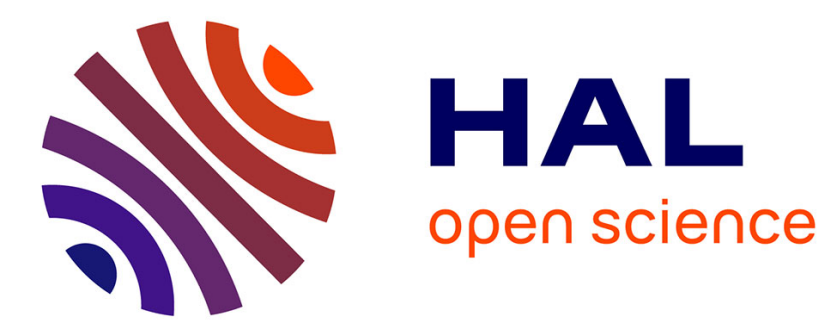

\title{
Hydrologic responses of the Zwalm catchment using the REW model: incorporating uncertainty of soil properties
}

\author{
A. El Ouazzani Taibi, G. P. Zhang, A. Elfeki
}

\section{To cite this version:}

A. El Ouazzani Taibi, G. P. Zhang, A. Elfeki. Hydrologic responses of the Zwalm catchment using the REW model: incorporating uncertainty of soil properties. Hydrology and Earth System Sciences Discussions, 2006, 3 (1), pp.69-114. hal-00298640

\section{HAL Id: hal-00298640 \\ https://hal.science/hal-00298640}

Submitted on 31 Jan 2006

HAL is a multi-disciplinary open access archive for the deposit and dissemination of scientific research documents, whether they are published or not. The documents may come from teaching and research institutions in France or abroad, or from public or private research centers.
L'archive ouverte pluridisciplinaire HAL, est destinée au dépôt et à la diffusion de documents scientifiques de niveau recherche, publiés ou non, émanant des établissements d'enseignement et de recherche français ou étrangers, des laboratoires publics ou privés. 
Hydrol. Earth Syst. Sci. Discuss., 3, 69-114, 2006

www.copernicus.org/EGU/hess/hessd/3/69/

Hydrology and

SRef-ID: 1812-2116/hessd/2006-3-69

Sciences

European Geosciences Union

Discussions

Papers published in Hydrology and Earth System Sciences Discussions are under open-access review for the journal Hydrology and Earth System Sciences

\section{Hydrologic responses of the Zwalm catchment using the REW model: incorporating uncertainty of soil properties}

\section{HESSD}

3, 69-114, 2006

Hydrologic responses of Zwalm catchment using the REW model

A. El Ouazzani Taibi et al.

Title Page

Abstract

Conclusions

Tables

A. El Ouazzani Taibi ${ }^{1}$, G. P. Zhang ${ }^{2}$, and A. Elfeki ${ }^{3}$

${ }^{1}$ Deveraux \& Deloitte Partnership, Environmental Expert Group, Emile Wauters Street, 121, 1020 Brussels, Belgium

${ }^{2}$ Department of Water Management, Delft University of Technology, P.O. Box 5048, 2600 GA, Delft, The Netherlands

${ }^{3}$ Department of Water Resources, Faculty of Meteorology, Environment and Arid Land Agriculture, King Abdulaziz University, P.O. Box 80208 , Jeddah 21589, Saudi Arabia

Received: 20 October 2005 - Accepted: 21 November 2005 - Published: 31 January 2006

Correspondence to: A. El Ouazzani Taibi (ouazzan1@ @otmail.com)

(C) 2006 Author(s). This work is licensed under a Creative Commons License.
Introduction

References

Figures

14

$\rightarrow 1$

4

Back

Close

Full Screen / Esc

Print Version

Interactive Discussion 


\section{Abstract}

The research presented in this paper focuses on an application of a newly developed physically-based watershed model approach, which is called Representative Elementary Watershed (REW) approach. The study stressed the effects of uncertainty of input 5 parameters on the watershed responses (i.e. simulated discharges). The approach was applied to the Zwalm catchment, which is an agriculture dominated watershed with a drainage area of $114.3 \mathrm{~km}^{2}$ located in East-Flanders, Belgium. Uncertainty analysis of the model parameters is limited to the saturated hydraulic conductivity because of its high influence on the watershed hydrologic behavior. The assessment of outputs uncertainty is performed using the Monte Carlo method. The ensemble statistical watershed responses and their uncertainties are calculated and compared with the measurements. The results show that the measured discharges are falling within the $95 \%$ confidence interval of the modeled discharge.

\section{Introduction}

15 The Representative Elementary Watershed (REW) approach, pioneered by Reggiani et al. $(1998,1999)$ and has been applied to investigate watershed hydrological responses in various context (e.g., Reggiani et al., 2000; Riggiani and Rientjes, 2005; Zhang et al., 2005; Zhang and Savenije, 2005). This study presents a new application of the REW approach to a catchment different from the previous research, especially attempting to look at parameter uncertainties using Monte Carlo simulation method.

The REW model approach was introduced as a new contribution in the development of physically-based hydrological models. There are different distributed physicallybased models among the current generation of hydrologic models that are listed and described in the literature. Nevertheless, it is important to introduce a short description

The distributed physically-based watershed models as introduced in first by Freeze

\section{HESSD}

$3,69-114,2006$

\section{Hydrologic responses of Zwalm catchment using the REW model}

A. El Ouazzani Taibi et al.

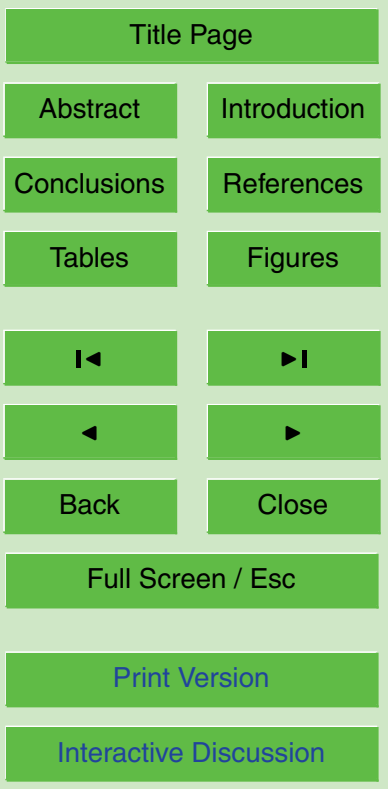

EGU 
(1978) are founded on rigorous numerical solution of partial differential equations (PDE) governing flow through porous media (Richard's equation, and Darcy's law), overland flow (kinematic wave equation) and channel flow (e.g. Saint-Venant equations). These equations also form the basis of other distributed watershed models 5 such as the "Système Hydrologique Européen" (SHE) model (Abbott et al., 1986).

There has been considerable discussion regarding the advantages and disadvantages of such distributed physically-based models by Beven (1989); Bathurst (1992); O'Connell and Todini (1996). Reggiani et al. (1998) state that while these models have the advantage that they explicitly consider conservation of mass, momentum and en10 ergy (but expressed at the point or REV scale), there is various shortcomings that need to be considered and cleared up.

Up to date, there is no general acceptable framework for describing the response of a hydrologic system which is applicable directly at the spatial scale of a watershed, which explicitly takes into account balances of mass, momentum and energy (i.e. without 15 having to use point-scale equations) and serves as a guideline for model development, field data collection and design applications.

Hence the aim of the REW approach was an attempt to fill this gap by formulating an approach that combines the advantages of the distributed and lumped approaches.

The procedure used in the REW model is motivated by the averaging approach pioneered by Hassanizadeh and Gray and published in a series of papers, e.g. Hassanizadeh and Gray (1979a, b, 1990). The averaging procedure is employed in order to derive watershed scale balance equations for mass, momentum, energy and entropy. The whole watershed is divided into smaller entities over which the conservation equations are averaged in space and time. The distributed description of the watershed is placed by an ensemble of interconnected discrete points. The ensemble of points has subsequently to be assembled by imposing appropriate jump conditions for the transfer of mass, momentum, energy and entropy across the various boundaries of the system. Furthermore, the large range of time scales typical for the various flows within a watershed requires additional averaging of the equations in time (Reggiani et

HESSD

3, 69-114, 2006

\section{Hydrologic responses of Zwalm catchment using the REW model}

A. El Ouazzani Taibi et al.

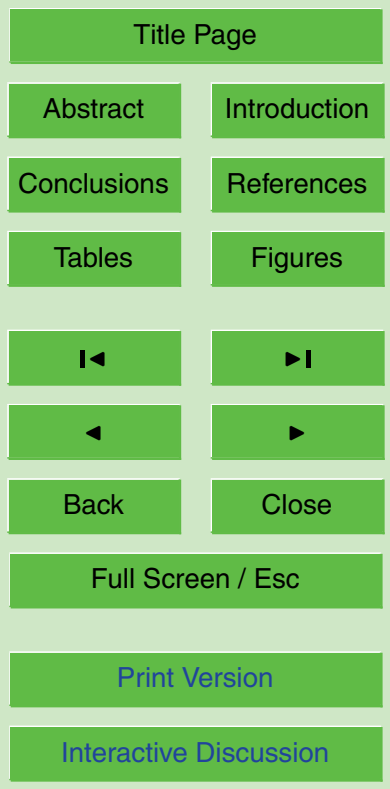

EGU 
al., 1998).

The REW-scale balance equations, obtained by the averaging procedure, represent the various REWs as spatially lumped units. Hence, the equations form a set of coupled non-linear ordinary differential equations (ODE), in time only; and only spatial variability 5 is allowed between REWs.

In the line of the REW approach (Reggiani et al., 1998), we will investigate, in the present study, effects of incorporating uncertainty in the saturated hydraulic conductivity $\left(K_{s}\right)$ on the Zwalm catchment (East Flanders, Belgium) responses in a stochastic framework, using the Monte Carlo simulation method.

\section{REW in a Monte-Carlo framework}

Monte Carlo (MC) method is the most widely used mean for uncertainty analysis, with various and widespread topics of applications. This method involves random sampling from the distribution of inputs and successive model runs until a statistically significant distribution of outputs is obtained.

15 In the current study, we will study the effects of the saturated hydraulic conductivity $\left(K_{s}\right)$ on the Zwalm catchment responses in a stochastic framework, using the Monte Carlo simulation method. This will lead to define an acceptable general stochastic framework for describing the response of the hydrologic system to atmospheric forcing, which is applicable directly at the spatial scale of a watershed and which takes into accounts the random character of as well system properties as the hydrological processes. This will be achieved as follows:

The procedure of incorporating uncertainty of the saturated hydraulic conductivity in the REW will be achieved as follows:

1. Divide the watershed into REW elements, on which the hydrologic properties are averaged, (e.g. topography, hydraulic conductivity, etc.).

\section{Hydrologic responses of Zwalm catchment using the REW model}

A. El Ouazzani Taibi et al.

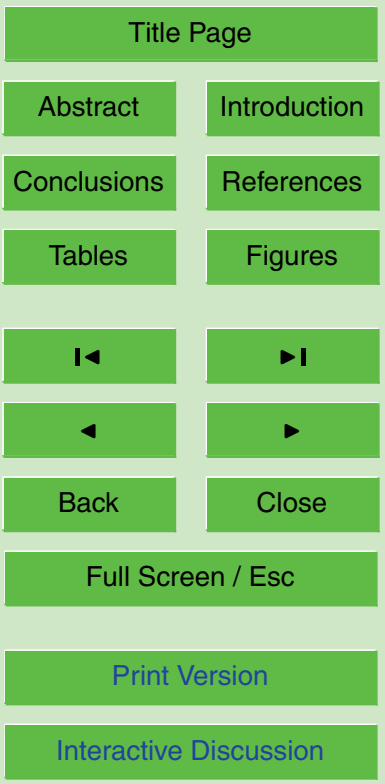

EGU 
2. Compute the weighted averaged saturated hydraulic conductivity over the watershed by assigning each soil texture zone in the watershed its corresponding minimum $\bar{K}_{s \min }$ and maximum $\bar{K}_{s \max }$ saturated hydraulic conductivity according to soil texture reference curves (Rawls et al., 1982). The weighted averaged saturated hydraulic conductivity is computed as $\bar{K}_{s}=\sum_{i=1}^{n} W^{i} K_{s}^{i}$, where $n$ is the number of soil texture types, the superscript $i$ indicates the particular soil type, and $W^{i}$ is weight factor of the particular soil type $i$ defined as the area of the particular soil texture zone divided by the area of the entire catchment.

3. Generate saturated hydraulic conductivity from a uniform distribution in the interval $\left[\bar{K}_{s \min }, \bar{K}_{s \max }\right]$ by the formula $\bar{K}_{s}=\bar{K}_{s \min }+\left[\bar{K}_{s \max }-\bar{K}_{s \min }\right] \times R A N D N$, where RANDN (random number) is generated from a uniform distribution on the interval $[0,1]$.

4. Run the REW model with a realization of the saturated hydraulic conductivity drawn from the uniform distribution in step 3.

5. Make a number of Mont Carlo cycles of the generated random saturated hydraulic conductivity and compute the output quantities for each realization (i.e. the discharge at outlet station).

6. Calculate ensemble averages of the quantities under consideration and a $95 \%$ confidence intervals as a measure of the uncertainty.

\section{Governing REW mass balance equations}

In the section, we focus on the final resulting mass balance equations that constitute the purpose of the present study, while the details of procedure used to derive the general REW balance equations of mass, momentum, energy and entropy, and the related balance equations for different subregions are reported in Reggiani et al. (1998).

\section{HESSD}

3, 69-114, 2006

Hydrologic responses of Zwalm catchment using the REW model

A. El Ouazzani Taibi et al.

Title Page
Abstract

Conclusions

Tables

\section{4}

$\triangleleft$

Back
Introduction

References

Figures

$\rightarrow$

Close
Full Screen / Esc

Print Version

Interactive Discussion 
However, in distributed watershed models, partial differential equations governing water flow zones are discretized and solved at scales much smaller than the REW. In the REW approach, balance laws for mass, momentum, energy and entropy for each flow zone are averaged over an REW. Thus, at point microscopic scale, the balance 5 equation written in terms of a generic thermodynamic property $\psi$ is given as follows

$\frac{\partial(\rho \psi)}{\partial t}+\nabla .(\rho \psi v)-\nabla . i-\rho f=G$

Upscaled balance laws are derived from Eq. (1) for each phase and each zone of an REW.

Hydrological thermodynamic properties may be exchanged across inter-subregion 10 boundaries or inter REW boundaries with neighboring REWs. Furthermore, within the unsaturated and saturated zones, the phases exchange the properties across phase interfaces (i.e. the water-soil, water-gas and solid-gas-interfaces). All these surfaces are assumed to be without inherent thermodynamic properties and, therefore, standard jump conditions apply between phases, subregions and REWs.

15 As shown in Reggiani et al. (1998), flow processes within the zones of a watershed are spread over a wide range of temporal and spatial scales. Examples of velocity and associated time scales are reported and published by Dunne (1978). This wide spectrum of time scales must be considered in the up-scaling of balance equations and constitutive relationships. This is achieved by defining average values over time as well as space. Balance equation is thereby integrated over a characteristic time interval $(t-\Delta t)$ to $(t+\Delta t)$, where $\Delta t$ must be selected in accordance with the particular problem under study.

We assign here that each REW may include the same functional entities found in the watershed. These functional entities are identified by the different flow types existing in 25 watershed, and occupy separate subregions, called zones. The zones are denoted with appropriate superscripts, i.e. $u$ (unsaturated zone), $s$ (saturated zone), c (concentrated overland flow), o (saturated overland flow), and $r$ (channel reach).

Thus, the resulting final mass balance equations for each subregion are as follows:

\section{HESSD}

3, 69-114, 2006

\section{Hydrologic responses of Zwalm catchment using the REW model}

A. El Ouazzani Taibi et al.

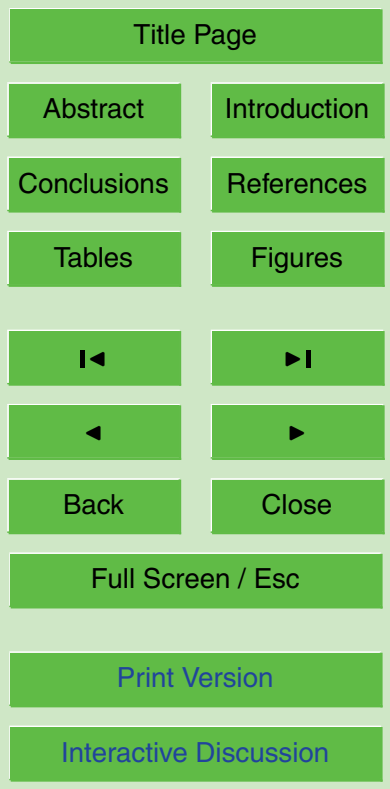

EGU 
- Unsaturated zone

$\frac{d}{d t}\left(\rho_{w}^{u} y^{u} \varepsilon^{u} s_{w}^{u} \omega^{u}\right)=\sum_{l} e_{w, l}^{u A}+e_{w, e x t}^{u A}+e^{u s}+e^{u c}+e_{w g}^{u}$

3, 69-114, 2006

- Saturated zone

$\frac{d}{d t}\left(\rho_{w}^{s} y^{s} \varepsilon^{s} \omega^{s}\right)=\sum_{l} e_{w, I}^{s A}+e_{w, e x t}^{s A}+e_{w}^{s b o t}+e_{w}^{s u}+e_{w}^{s o}+e_{w}^{s r}$

- Saturated overland flow

$\frac{d}{d t}\left(\rho^{o} y^{o} \omega^{o}\right)=e^{o t o p}+e^{o c}+e^{o s}$

- Concentrated overland flow

$$
\frac{d}{d t}\left(\rho^{c} y^{c} \omega^{c}\right)=e^{c t o p}+e^{c u}+e^{c o}
$$

- River channel

$$
\frac{d}{d t}\left(\rho^{r} m^{r} \xi^{r}\right)=\sum_{l} e_{l}^{r A}+e_{e x t}^{r A}+e^{r t o p}+e^{r s}+e^{r o}
$$

where $\omega^{i}, i=u, s, O, c, r$, is the area fractions of the surface of zone $i$ within the total REW after projection onto the horizontal plane, $y^{i}$ the average depth of zone $i, m$ is the average channel flow area, and $/$ is the average channel length.

The mass exchange terms $e^{i j}$ are unknown quantities of the problem, and are generally functions of the mean values of the velocity on both sides of the boundary and the difference in the hydraulic potentials $(p+\zeta \rho g)$, with $\zeta$ is the elevation at the centre of zone, and $p$ is the average pressure of zone $i$. However, a proposed linearization that is used in the current study as constitutive relationship has been proposed, and the detail can be found in Reggiani et al. (2000).

Hydrologic responses of Zwalm catchment using the REW model

A. El Ouazzani Taibi et al.

Title Page

\section{Abstract}

Conclusions

Tables

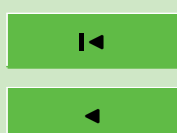

Back

Full Screen / Esc

Print Version

Interactive Discussion 


\section{Description of the Zwalm catchment}

The Zwalm catchment is situated about $20 \mathrm{~km}$ south of Ghent in East-Flanders, Belgium $\left(50^{\circ} 45^{\prime} 48^{\prime \prime} \mathrm{N}\right.$ to $50^{\circ} 54^{\prime} 16^{\prime \prime} \mathrm{N}$, and $3^{\circ} 40^{\prime} 17^{\prime \prime} \mathrm{E}$ to $\left.3^{\circ} 50^{\prime} 15^{\prime \prime} \mathrm{E}\right)$. The Zwalm stream is a tributary of the Scheldt River. Figure 1 shows the Zwalm catchment together with 5 the gauged sub-catchments. Troch et al. (1993) gave a general overview of the soil, vegetation, and topographic conditions of the catchment.

The total drainage area of the Zwalm catchment at the gagging station is $114.3 \mathrm{~km}^{2}$ and the total length of perennial channels is $177.5 \mathrm{~km}$. The degree of urbanization in the catchment is about $10 \%$ with urbanized areas mainly situated in the North-East

10 (Zottegem) and clustered in three small villages. The surface soils mainly consist of Tertiary and Quaternary deposits. During the last glacial period (Wurm glacial) the tertiary layers in the catchment were covered by aeolian sandy-loam and loam soils. This cover is estimated to be between 0 and $15 \mathrm{~m}$ deep, depending on the geomorphologic characteristics of the region, and is estimated to range between $0 \mathrm{~m}$ - on steep slopes $15(>7 \%)$, oriented to the South - and $15 \mathrm{~m}$ - on mild slopes $(<2 \%)$, oriented to the East. The valley bottoms were partly covered with alluvium (originating from soil erosion on the steep slopes) and peat during the Holocene. According to the Belgian Soil Map, minor isolated patches of sand and clay cover less than $5 \%$ of the total catchment area. Figure 2 shows the soil types that cover the Zwalm catchment. Land use is mainly arable crop farming and permanent pasture, while the South of the catchment is partly forested.

The local hydraulic conductivity is measured by means of the constant head method. The mean value and the standard deviation given by Troch et al. (1993) are based on 10 to 15 measurements for each soil type. The topography of the basin is characterized by to $150 \mathrm{~m}$. Figure 3 shows the digital elevation model (DEM) of the Zwalm catchment. The resolution of the DEM is $30 \mathrm{~m} \times 30 \mathrm{~m}$. Climate conditions can be described as humid temperate. The yearly mean air temperature is $10^{\circ} \mathrm{C}$, the average of the coldest

\section{HESSD}

$3,69-114,2006$

\section{Hydrologic responses of Zwalm catchment using the REW model}

A. El Ouazzani Taibi et al.

\section{Title Page}

\section{Abstract}

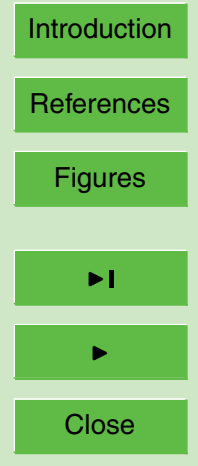

Back

Close

Conclusions

Tables

14

4

Full Screen / Esc

Print Version

Interactive Discussion 
month (January) is $3^{\circ} \mathrm{C}$, and the average of the warmest month (July) is $18^{\circ} \mathrm{C}$. The mean yearly rainfall is $775 \mathrm{~mm}$ and is distributed evenly over the year. The annual evaporation is approximately $450 \mathrm{~mm}$. The Zwalm catchment is described in detail in De Troch (1977). The discharge data used in this study were collected at the outlet 5 of the Zwalm catchment. Precipitation data are available, with many data gaps, from five different stations from 1991 onwards at a $10 \mathrm{~min}$ interval, and hourly temperature, humidity, radiation and wind data are available from 1991 through 1993. Discharge measurements at the outlet of the Zwalm catchment are available from 1982 onwards, and for the subcatchments from 1991 onwards.

10 A continuous hourly meteorological dataset was prepared from 1994 onwards based on daily observations of air and dew point temperature, solar radiation, wind speed and precipitation, from the climatological station located in Kruishoutem (see Fig. 1), approximately $5 \mathrm{~km}$ outside the catchment (KMI, 1994-1999). The daily data, except for the precipitation, were resampled into hourly time-steps based on the diurnal cycle of the hourly observations from 1991 to 1993.

The daily precipitation was resampled into hourly time-steps by rescaling hourly observations from the weather station of Uccle (located approximately $10 \mathrm{~km}$ outside Brussels) to the weekly totals of the Kruishoutem weather station. As the distance between both stations is approximately $50 \mathrm{~km}$ only, and the weekly totals for both stations show a very good agreement, it is assumed that using this interpolation method the reliable storm statistics at Kruishoutem are preserved (Pauwels et al., 2002). This interpolation method will cause a small error in the timing of the discharge peaks, but given relatively the short distance between the two stations, therefore, the error can practically accepted. Further, a digitized Digital Elevation Model (DEM), a digital soil texture map from the Belgian National Geographic Institute, and a SPOT-derived land cover classification from 3 August 1998, are available at a $30 \mathrm{~m}$ resolution (see Fig. 3).

HESSD

3, 69-114, 2006

\section{Hydrologic responses of Zwalm catchment using the REW model}

A. El Ouazzani Taibi et al.

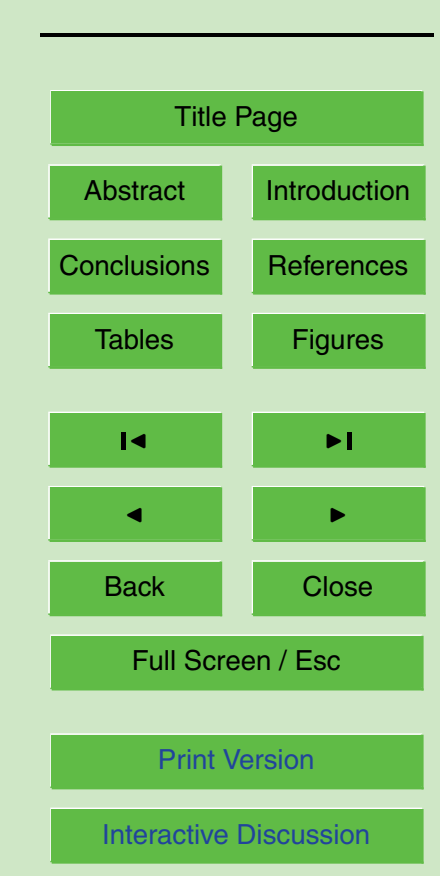




\section{REW model calibration and validation}

\subsection{Overview}

Model calibration consists of changing values of model parameters in an attempt to match field conditions within an acceptable range. This requires that field conditions 5 at a site are properly characterized. Lack of proper site characterization may result in a model that is calibrated to a set of conditions which are not representative of actual field conditions. It implies also that parameters of hydrologic models can not always be determined directly. Model parameters are often not well defined and subject to an extreme degree of variations due to the intrinsic spatio-temporal variability of hydrologic system properties. The calibration of physically based models is not a straightforward task due to the large number of model parameters involved and the computational requirements of making multiple model runs. A set of calibrated parameters will generally represent one possible combination that, in conjunction with the particular model structure and solution scheme used, produces a response similar to that observed. Physically-based models are best suited to research applications, in which they are used to explore the implications of making different assumptions about the nature of hydrological system characteristics and parameters.

It is evident that the success of any calibration procedure is highly dependent on the nature (quantity and quality) of the data used. It has often been suggested that the calibration data should be representative for the various phenomena experienced by the watershed. The latter point relates to the choice of a proper objective function. Such a choice should reduce the sensitivity of the estimation results to the type and quality of the calibration. It will be noted that there is many criteria that have been proposed and discussed (Nash and Sutcliff, 1970; Aitken, 1973; Sharma and Luxmore, 1979;

Martinec and Rango, 1989; Lettenmaier and Wood, 1993), because none of them satisfy all model calibration. This leads to define new criteria or redefine old ones in order that their values reflect a model quality in the way that will be regarded as the best.

3, 69-114, 2006

\section{Hydrologic responses of Zwalm catchment using the REW model}

A. El Ouazzani Taibi et al.

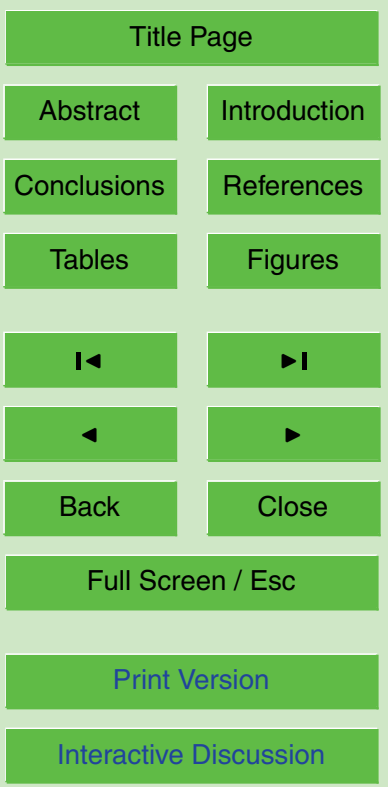

EGU 
There may be many parameter sets that lead to acceptable simulations of a given set of observations. Definitions of acceptability may vary according to context. For example, if a hydrological model is evaluated in terms of simple goodness-of-fit function, less good values of this function may be considered acceptable for simulations 5 of a time period known to cause particular difficulties for the model. Here, the allowance can be made through the Monte-Carlo simulations (MCS) within the explicit definition of acceptability by rejection of simulations for which the criteria of acceptance are not achieved. Hence, the threshold criteria of acceptance adopted here within the calibration procedure is restricted to the good fit of simulated discharge hydrograph, 10 in comparison with observations in terms of percent bias (PBIAS) criterion, supplemented by computed statistical parameters that need to be physically and statistically significant. The choice of the PBIAS as objective function is support by the fact that is the most used objective function (Aitken, 1973; Sharma and Luxmore, 1979; Martinec and Rango, 1989; Lettenmaier and Wood, 1993), mainly as the output function that will be calibrated in the current case is the discharge response, as illustrated in the Eq. (7). The detailed description of the adopted objective function is reported in the validation procedure Sect. 5.4. The percent bias (PBIAS) is defined as follows:

PBIAS $=\frac{\bar{Q}_{\text {sim }}-\bar{Q}_{\text {obs }}}{\bar{Q}_{\text {obs }}} \times 100$

\subsection{Data used}

20 Beyond the characterization of Zwalm catchment data, it seems interesting with respect to the REW model components structure, to define the used soil type and atmospheric forcing that are the major interesting components of model run. However, generally soil types are characterized by a pore disconnectedness index $\lambda$ and a pore-size distribution index $\mu$, in addition to the porosity that is necessary to complete characterization
HESSD

3, 69-114, 2006
Hydrologic responses of Zwalm catchment using the REW model

A. El Ouazzani Taibi et al.

\section{Title Page}

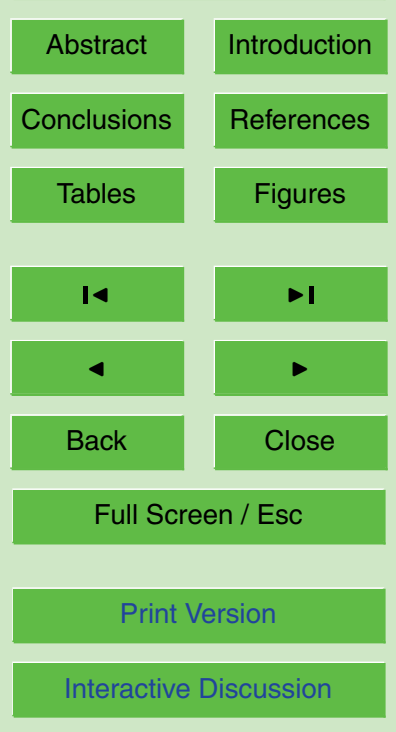

EGU 
over volume of voids, such that

$P_{\text {cap }}(s)=\rho g \psi_{b} s^{-1 / \mu}$

where $P_{\text {cap }}$ is the capillary pressure and $\psi_{b}$ is the air entry (or bubbling capillary) pressure head. The effective hydraulic conductivity $K(s)$ in the unsaturated zone under 5 unsaturated condition $(s<1)$; can related to the saturated hydraulic conductivity $K_{s}$ via the relationship

$K(s)=K_{s} s^{\lambda}$

The two indices $\lambda$ and $\mu$ can be reconciled by integrating the simplified Burdine (1958) equation governing the relationship between permeability and capillary pressure, such 10 that

$\lambda=3+2 / \mu$

However, Eqs. (8) and (9) are point scale equations and will apply to the current study only if the soils in the subsurface zone can be assumed to be uniform. For heterogeneous soils the above relationships will change from point to point within the REW.

15 On other hand, the great impact of hydraulic conductivity variability on the hydrologic system responses is well known. However, in our approach, the heterogeneity cannot be modeled explicitly (lumped model parameters), nevertheless, the effects of this variability is included assuming the saturated hydraulic conductivity (i.e. effective hydraulic conductivity) as random variable, using the Monte Carlo simulation method.

20 On the other hand, and for the atmospheric forcing, Eagleson (1978) suggested that the rainfall inputs can be considered as Poisson arrival process, of independent rainfall events whose duration are experimentally, with constant intensities (i.e. rectangular pulses) drawn from either an exponential or a gamma distribution. In our cases, the stochastic nature of atmospheric forcing is ignored. In other words, atmospheric forc-

ing is considered to be uniformly distributed over the entire Zwalm catchment, i.e. this simple representation is subject to obvious limitations based on the fact that seasonal variation and forms of random rainfall variability are ignored.
HESSD

3, 69-114, 2006

\section{Hydrologic responses of Zwalm catchment using the REW model}

A. El Ouazzani Taibi et al.

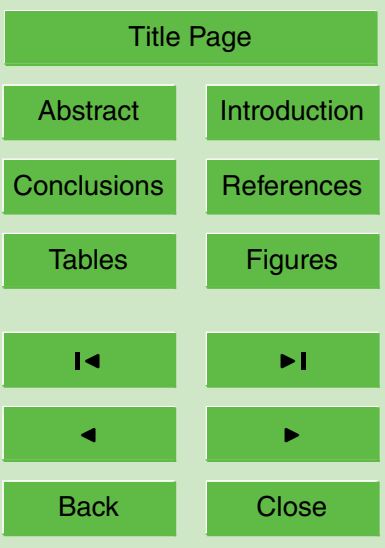

Full Screen / Esc

Print Version

Interactive Discussion 


\subsection{Calibration procedure}

During the calibration procedure, specific initial/boundary conditions can be introduced (if known) or generated automatically by the model in the preprocessor step of model running (Zhang et al., 2003, 2005). For the present study of Zwalm catchment case, 5 the initial/boundary conditions have been generated by the REW model. The global input parameters system used can be subdivided into two kinds namely: model input parameters (physical input data, i.e. topography, soil properties, etc.), and model calibration parameters (expressed in terms of station hydraulic geometry coefficients and exponents that are based on empirical studies of Leopold and Maddock, 1953). The 10 physical model parameters are obtained from the measured Zwalm catchment data and/or derived from the Brooks and Corey (1964) formula, while the calibration parameters are chosen intuitively. The intuitive choice is dictated by optimizing well defined simulated discharges in comparison with observations (i.e. by optimizing the goodnessof-fit of predictive discharges with observations according the PBIAS criterion of mean 15 simulated discharge assumed as quality objective function of model calibration). For the current application, the calibration procedure was carried out manually by combining systematically the two sets of parameters mentioned above.

The REW model calibration has been conducted for two major cases, underlying the corresponding two Strahler order attributed to the main river channel. The chosen Strahler order leads to a specific generated number of REWs (sub-catchments). However, the two cases reported here correspond to a Strahler order 3 and 2 that involve the study of water balance on the Zwalm catchment discretized into 9 and 43 REWs, respectively, as shown in Figs. 4 and 5. The calibration for Strahler 1 (corresponding to 213 REWs) has not been performed, because the REW model is not able to handle the hydrologic responses of the 213 REWs at the moment.

On the other hand, according to the study of the sensitivity of the resulted estimations to variability in calibration data, it was decided to choose for this purpose 5 years records, from 1994 through 1998. The choice of the entire period for the calibration

\section{HESSD}

$3,69-114,2006$

\section{Hydrologic responses of Zwalm catchment using the REW model}

A. El Ouazzani Taibi et al.

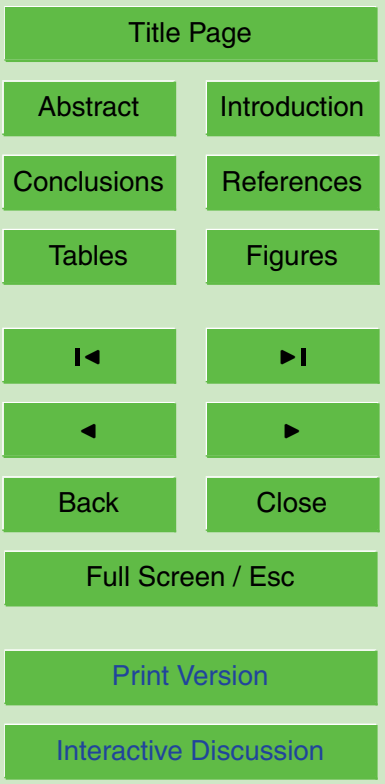

EGU 
procedure is justified by the fact that as longer calibration periods are used, the parameters tend to attain realistic values (Sorooshian et al., 1993).

- Case 1

In the case 1 (Strahler order 3 ) the Zwalm catchment is discretized into 9 REWs as shown in Fig. 4. According the selected objective function (i.e. percent bias statistic defined by Eq. 7), the calibration has been dictated by minimizing the mean simulated discharge error. Hence, the best calibration leads to a low PBIAS $(8.48 \%)$. It was accomplished by the simultaneous combinations of model parameters, as described above. From the best resulting calibration on the time period 1994-1998, the comparison between the simulated and observed discharges through the line $1: 1$ gives a low RMSE $\left(1.836 \mathrm{~m}^{3} . \mathrm{s}-1\right)$ and a reasonable high correlation coefficient (0.577) as shown in Fig. 6.

Based on the above criterion of acceptance and the goodness-of fit of total hydrograph, the resulting simulations show a good behavior of the hydrologic responses of Zwalm catchment. On the other hand, the discrepancies between simulations and observations illustrated by the RMSE and correlation coefficient criterions can be attributed to the series of discharge peaks distributed over the entire time period (Fig. 6).

\section{- Case 2}

In case 2 (Strahler order 2), the Zwalm catchment is discretized into 43 REWs as shown in Fig. 5. In the guideline of the calibration procedure carried out in case 1, the best calibration leads to a lower PBIAS of (6.57\%). Further, examining Fig. 7, one can note a lower RMSE $\left(1.742 \mathrm{~m}^{3} . \mathrm{s}^{-1}\right)$ and an almost similar correlation coefficient $(0.569)$ through the regression analysis. On the other hand, from the above results, one notes that the predictive hydrographs represent the observed catchment response.

On the basis of PBIAS criterion of model predictions introduced above, it can be seen that the total simulated discharge is overestimated, in accordance with

\section{Hydrologic responses of Zwalm catchment using the REW model}

A. El Ouazzani Taibi et al.

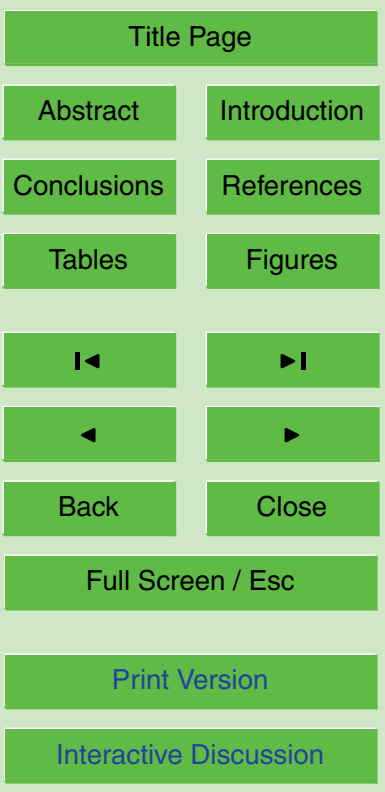

EGU 
what can be expected knowing that the model is performed without land cover consideration.

Using the current calibrated parameters set, the resulting simulated hydrographs obtained for each year are separately shown in Fig. 8. These hydrographs will be described in details in the validation section.

\subsection{Validation procedure}

In order to establish the reliability of the results of an estimation procedure, it is important to ensure that the parameter values satisfy the following two conditions:

(1) The values of the input parameters are physically realistic;

10 (2) The confidence in the ability to forecast using these values is high.

With respect to (1), the estimated parameter values were checked against the reasonable range suggested by the in situ measurements and the values listed in the references according the real system properties. Regarding (2), the parameter set obtained using the calibration procedure was used to generate a discharge hydrograph for the forecast period, with which the model predictions are compared with observations. Therefore, the following statistical measures were employed: the percent bias (PBIAS) of the mean simulated discharge residuals, the RMSE (Root Mean Square Error) and correlation coefficient $R$. These values were calculated for each discharge series to examine and detect the deficiencies in the simulation of various aspect of the hydrograph.

Each discharge series mentioned above is defined over a one year time period, chosen on 5 years period from 1994 through 1998. Normally, a good estimation procedure should result in minimizing the values of PBIAS and RMSE as much as possible, consistently close to zero. In the current case, however, we refer here to two cases presented above (i.e. 9 and 43 REWs) and the corresponding calibration parameter sets, with which the resulting values of the above statistical measures are computed for each year and listed in Table 1.

\section{Hydrologic responses of Zwalm catchment using the REW model}

A. El Ouazzani Taibi et al.

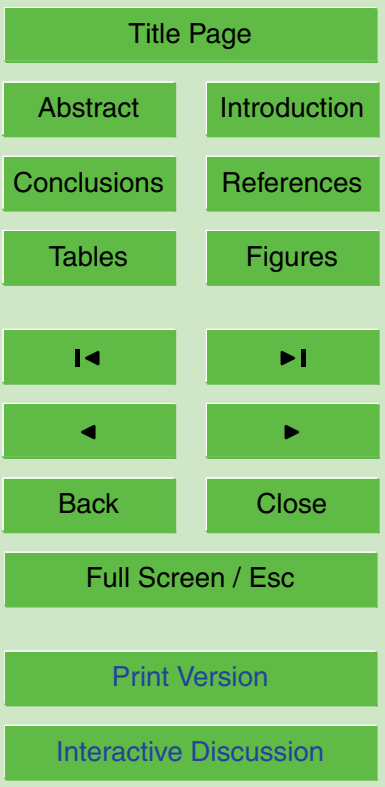

EGU 
Examining Table 1, one can note that the model is well validated in both cases. We can observe low PBIAS and RMSE for the five years, and especially a quite high correlation coefficient for 1995, within case 2 as can be illustrated by the frequency distribution of simulated and observed discharges in Fig. 9.

From Table 1, we found a reduction of PBIAS and RMSE by increasing the number of REWs. This is due to the improved accuracy by simulating the water balance on greater number of REWs of small scale. However, regarding the above results, we should compute the REW model uncertainty according to the model parameters of case 2 that seems more appropriate for our model analysis. This can allow us to 10 analyze the degree to which the REW model results are affected by uncertainty in model parameters, restricted here to saturated hydraulic conductivity, that have a large effect on the dynamics of hydrologic processes occurring at watershed scale.

\section{Uncertainty analysis of the REW model}

A systematic uncertainty analysis provides insight into the level of confidence in model 15 estimates, and can aid in assessing how various possible model estimates should be weighed. Further, it can lead to the identification of the key sources of uncertainty (such as data gaps) which merit further research, as well as the sources of uncertainty that are not important with respect to a given response. The purpose of such quantitative uncertainty analysis is to use currently available information in order for quantifying the degree of confidence in the existing data and models. The purpose is not to somehow "reduce" uncertainty - reduction in uncertainty can only come from gathering additional information and filling "data gaps".

Following the guideline presented in the obvious section, we will analyze the degree to which the REW model results are affected by uncertainty in model input parameters through a Monte Carlo simulation method. In fact, Monte Carlo (MC) method is the most widely used mean for uncertainty analysis, with various and widespread topics of applications. This method involves random sampling from the distribution of inputs and

\section{HESSD}

$3,69-114,2006$

\section{Hydrologic responses of Zwalm catchment using the REW model}

A. El Ouazzani Taibi et al.

Title Page
Abstract

Conclusions

Tables

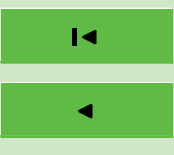

Back
Introduction

References

Figures

$\rightarrow$

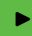

Close
Full Screen / Esc

Print Version

Interactive Discussion 
successive model runs until a statistically significant distribution of outputs is obtained.

In the current application, MCS of output uncertainty of the Zwalm catchment response through REW model is established. The uncertainty in the model parameters is restricted to weighted saturated hydraulic conductivity $\bar{K}_{s}$ according to the range of 5 interval values listed in Table 2, and following a uniformly distributed probability density function over the interval $\left[\bar{K}_{s \text { max }}, \bar{K}_{s \text { min }}\right]$. MCS are performed through the REW model under lumped mode and without land cover consideration. Figure 10 shows the MCS procedure adopted here to produce the corresponding output discharge. The convergence of the MCS has been investigated using 10, 20, 30, 40,50,60,70, 80,90, and 10100 realizations as shown in Fig. 11. Converges has been reached after 60 realizations. This result can be supported by computation of objective functions, such that mean discharge error (bias), standard deviation of bias, and PBIAS that are calculated and plotted for each realization. Figure 12 illustrates that mean discharge error, STD of mean discharge error, and PBIAS converge to constant values, from 60 realizations.

15 Besides, the uncertainty bounds of simulated hydrograph can be calculated according to $95 \%$ confidence limits by indicating "mean \pm 2 STD" and presented as shown in Fig. 13.

The use of the standard deviation to estimate the limits of the confidence interval (in this case the $95 \%$ confidence interval) is directly dependent on the probability distribution of the data set or the probability function chosen to represent the data set. For some probability distributions, including the one discussed later, there are analytical relationships that relate the standard deviation to the required confidence intervals. Usually, a normal distribution is assumed for the variable under consideration; in this case, the confidence limits are symmetric about the mean. For a 95\% confidence in25 terval, the confidence limits are approximately 2 standard deviations of the variables, above and below the mean.

However, regarding the resulting of the mean simulated discharges, one can note that the REW model is very sensitive to the saturated hydraulic conductivity as shown in Fig. 14, in which the mean simulated discharge increase with the increase of the

\section{Hydrologic responses of Zwalm catchment using the REW model}

A. El Ouazzani Taibi et al.

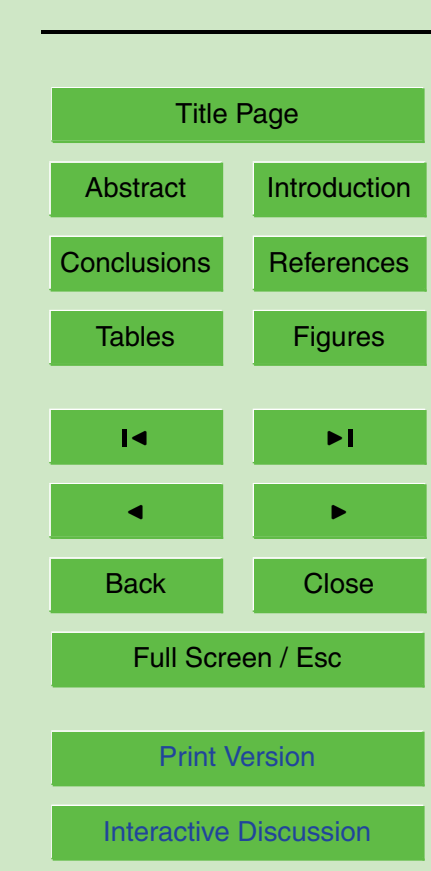

EGU 


\section{Discussion}

When using physically-based models in hydrology, Beven (1989) advocated that the predictions of these types of models must be associated with estimates of predictive uncertainty. This study has been undertaken in this way to test the performance of the REW model and exploration of the MCS technique for uncertainty estimation and evaluating the predictions of the model. We are limited here to uncertainty calculations of saturated hydraulic conductivity and its hydrological responses. The results of this study, of which a part has been introduced in the previous sections, suggest that we should expect the uncertainty bounds for the physically-based REW model to be quite wide, even when parameter values have been constrained by calibration.

The effects of the uncertainty of the model parameters raise a number of points. It has been shown here for the case of Zwalm catchment that for the prediction of hydrologic watershed responses, changes in the simulated hydrograph resulting from sults emphasize the importance of suitable parameter estimation from field measurements to improve the catchment characteristics, and therefore, reduce the uncertainty bounds. An interesting conclusion arising from this, is how uncertainties associated with both the calibration procedure and the model predictions following the model parameters can be constrained.

However, in the obvious case of model calibration, it has been possible to constrain the estimated uncertainty ranges by incorporating more observed data in the calibration procedure and optimizing the selected objective functions. A longer period of observed discharges, observations of parameter values, and observations of internal state variimportant point to note in this respect, however, is that it may be difficult to make parameter and internal state measurements that are of a very different scale, regard-

\section{Hydrologic responses of Zwalm catchment using the REW model}

A. El Ouazzani Taibi et al.

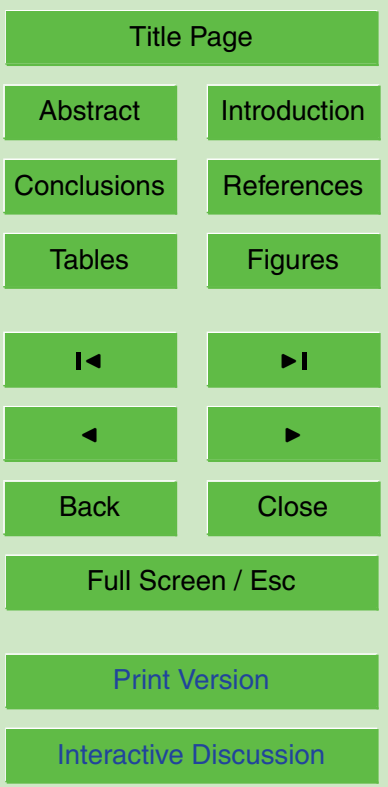

EGU 
ing the model structure that is lumped. As defined above, the MCS were performed on 100 realizations, according a random weighted $K_{s}$ uniformly distributed on an interval $\left[\bar{K}_{s \text { max }}, \bar{K}_{s \text { min }}\right]$, ranging between a minimal and maximal values that correspond to $1.9910^{-6} \mathrm{~m} . \mathrm{s}^{-1}$ and $1.3710^{-5} \mathrm{~m} . \mathrm{s}^{-1}$, respectively. However, from the calibration 5 procedure performed on the period 1994-1998, and in terms of PBIAS criterion, we note that the mean simulated discharge is underestimated for the case of $\bar{K}_{s \text { min }}$ and overestimated for $\bar{K}_{s \text { max }}$, in comparison with observations to a PBIAS of $-14.17 \%$ and $70.72 \%$, while the RMSE criterion is of order of $1.83 \mathrm{~m}^{3} . \mathrm{s}^{-1}$ and $2.87 \mathrm{~m}^{3} . \mathrm{s}^{-1}$, respectively. In other words, changing the $K_{s}$ values downward by $50 \%$ and upward by $25 \%$ 10 versus the calibrated $K_{s}$ leads to a shift of the model discharge bias decreasing by $22.65 \%$ and increasing by $64.15 \%$, respectively. Further, if we consider the model run separately for each year of record, and also in terms of PBIAS criterion, the best result for model run with calibrated parameters correspond to 1995 period, in which the simulated discharge present a PBIAS of $6.18 \%$, and the regression analysis gives relatively 15 high correlation coefficient (0.759) and low value of RMSE criterion $1.687 \mathrm{~m}^{3} . \mathrm{s}^{-1}$. We emphasize that the higher RMSE and/or low correlation coefficient can be attributed to the hydrograph peaks, e.g. those clearly recorded for 1996 in the period of September, shown in Fig. 15a with a relative lower correlation coefficient $(0.475)$ that increase when the erroneously model discharge is removed given a value of 0.536 . Further, for 20 the case of 1996 period, the same remarks are noted for the model run with $\bar{K}_{s \min }$ and $\bar{K}_{s \max }$ (see Table 4). On the other hand, from Table 1 one can emphasize that most discrepancies are noted in 1997 through a lower correlation coefficient (0.314), as can be illustrated by the frequency distribution of observed and simulated discharges shown in Fig. 16. A particular case can be seen for 1998, in which one notes a good estimation 25 of the mean discharge regarding the low PBIAS (4.89\%), while the hydrographs are poorly correlated (0.444). This can be attributed to discrepancies between observed and simulated discharge peaks in the time period of September-December (Fig. 17).

As can be seen in Fig. 13, the computed uncertainty bounds envelope well the observed discharge in the major proportion of the hydrographs, except for some places

\section{Hydrologic responses of Zwalm catchment using the REW model}

A. El Ouazzani Taibi et al.

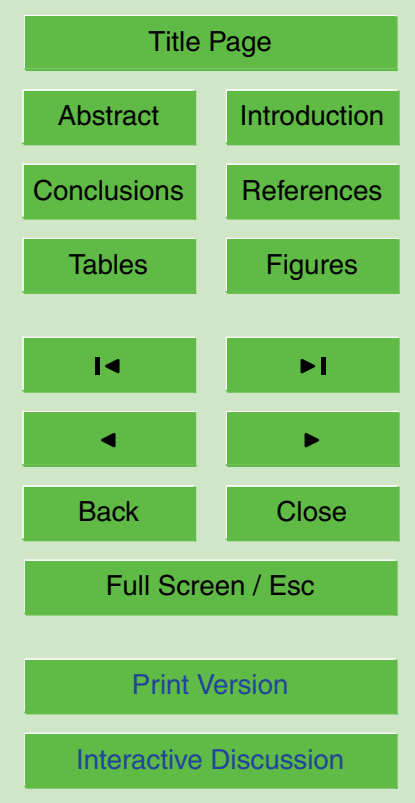

EGU 
the beginning of discharge hydrographs in 1996 and 1997, in which the observations are slightly outside the uncertainty bounds. This can be attributed mainly to initial conditions and to simplifying assumptions described obviously. Nevertheless, it remains plausible to say that on the basis of the above results, the REW model is quite sen5 sitive to $K_{S}$ that is illustrated through the dynamic of the mean simulated discharges (i.e. in terms of PBIAS criterion) and the little wide uncertainty bounds, and has a good predictive capacity of hydrologic system responses.

It is noted that even though the time-spatial variability of atmospheric forcing (e.g. rainfall) plays an important role in the process of watershed runoff generation, 10 climatic inputs are considered in a simple representation, underlying a uniform distribution in the application of REW model to predict hydrological behavior of Zwalm catchment. Often the hydrologic models have e.g. rainfall measured by only one gauge, or a few gauges. However, the REW model parameters have been estimated by calibration using an average rainfall uniformly distributed throughout the Zwalm catchment. This 15 simple representation of atmospheric forcing is subject to obvious limitations based on the fact that seasonal variations and forms of random rainfall variability have been ignored. This assumption may introduce significant uncertainty in the system parameters (i.e. soil moisture, hydraulic conductivity, infiltration, etc.) when they are based on a comparison of observed and predicted hydrologic responses, knowing the effects of seasonality of climatic inputs and the randomness of storm and interstorm climatic forcing.

In the present case, the uncertainty is considered through saturated hydraulic conductivity input only and not explicitly included as spatial variable in model structure. This leads to the fact that for each chosen random $K_{s}$, the uncertainty is included through the effective hydraulic conductivity $\left(K_{\text {eff }}\right)$ as function of soil saturation (i.e. soil moisture curve) according to Eq. (9), and through the plotted curve of $K_{\text {eff }}$ shown in Fig. 18. Figure 18 shows the dependence of $K_{\text {eff }}$ on the soil moisture content, although the real trend encountered under field conditions is not reflected. This is because, the soil moisture are well dependent on the antecedent soil moisture conditions and cli-

HESSD

3, 69-114, 2006

\section{Hydrologic responses of Zwalm catchment using the REW model}

A. El Ouazzani Taibi et al.

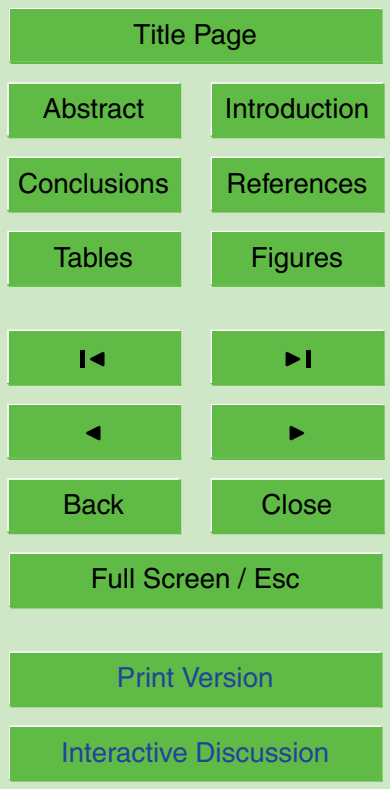

EGU 
matic inputs variability. In general, the watershed has an interacting effect on rainfall both in time and space, and the complex relationship among the degree of spatial and seasonal variability of rainfall, watershed characteristics (topography, channel network, soils, etc.), antecedent soil moisture conditions and watershed response is poorly un5 derstood (Shah et al., 1996). Further, changing $K_{s}$ the infiltration becomes strongly affected, which influences the subsurface hydrologic processes that are related to variables which control the hydraulic conductivity and moisture characteristic curve of the soil.

It is widely recognized that on natural hillslope, random spatial variability of soil 10 hydraulic properties confounds the understanding and computation of infiltration and runoff (Loague and Gander, 1990). However, due to the structural properties of soils and their scale, the density and spatial characteristics of the ground cover and the root structure in grasslands, that are not reported in this study, it is not possible to interpret explicitly and quantitatively the physical processes responsible for the variability.

15 To examine the effect of spatially variable infiltration on runoff, several authors have combined MCS of the distributions of soil properties with physically-based models of percolation and sheet flow. Nevertheless, the results presented above lend a good credibility to the model structure and the dynamic that seems justified, regarding its sensitivity to hydrologic parameters uncertainty. This has been illustrated by increasing mean predicted discharges according the increasing $K_{s}$ and quite wide uncertainty bounds that envelope well the observed discharge. On the other hand, we must emphasize that with respect to discrepancies noted above, the limitations in the model theory and parameterization, that are discussed obviously need to be included explicitly in the model structure in order to improve the model predictions (or performance).

25 It is noted that from the results, there is an improvement of model prediction in term of PBIAS criterion when the catchment is discretized into a high number of REWs. This leads to say that implementing the REW for the case of stream Strahler order 1, relating to $213 \mathrm{REWs}$, the model performance will most probably be improved.

On the other hand, we must point out here the importance and impact of calibration

HESSD

3, 69-114, 2006

\section{Hydrologic responses of Zwalm catchment using the REW model}

A. El Ouazzani Taibi et al.

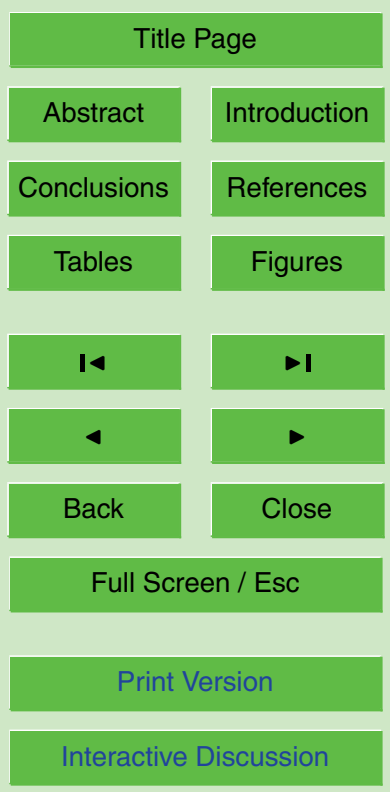

EGU 
procedure that contributes significantly to the accuracy of rainfall-runoff model. Owing to the general nature of rainfall-runoff models their application to any given watershed requires that the values of the parameters of the functions representing the various subprocesses of the overall system be identified for that particular watershed. Further, an 5 interesting point concerns the selection of the objective function that has been rather subjective as reported in major part of the literature. However, if the selected objective function lacks a proper description of both the stochastic elements of the data and the physical situation, it is likely that the estimated parameters may not assume values that are close approximations of their true and acceptable values. The consequence of 10 using such parameter estimates is the likely cause of model divergence in rainfall-runoff simulation studies.

\section{Conclusion}

The assessment of outputs uncertainty due to the uncertainty in the model parameters were performed using the Monte Carlo method through REW model. The uncertainty in model parameters has been restricted to saturated hydraulic conductivity $\left(K_{s}\right)$. However, the framework was modeled after a generation of a set of four series of generated random saturated hydraulic conductivity from a uniform distribution on the interval $\left[K_{s \min }, K_{s \max }\right]$. The chosen intervals were obtained from soil texture reference curve of Rawls et al. (1982). It has been shown that the REW model was performed

under lumped mode and without land cover consideration. The uncertainty in REW model outputs is illustrated by the uncertainty bounds that envelop well the discharge observations. Furthermore, the calculated statistical parameters (PBIAS, RMSE, correlation coefficient, etc.) lead to note that the REW model structure and components have ability to predict the hydrologic responses occurring at the watershed scale, that emphasized that the model has been performed within a set of simple assumptions, of which, the details of topographic features (such as convergence and divergence) spa-

\section{HESSD}

3, 69-114, 2006

\section{Hydrologic responses of Zwalm catchment using the REW model}

A. El Ouazzani Taibi et al.

Title Page
Abstract

Conclusions

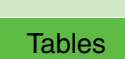

Tables

14

$\triangleleft$

Back

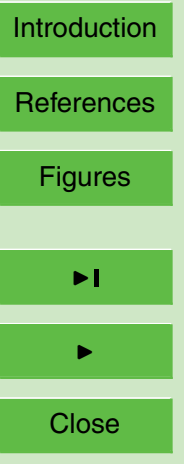

Full Screen / Esc

Print Version

Interactive Discussion 
tial variability of soils, randomness of storm arrivals and storm duration, seasonality of both rainfall and potential evapotranspiration, and spatial variability of rainfall has not been considered. The discrepancies in the model output noted obviously are related to uncertainty in the model parameters (such that saturated hydraulic conductivity) as well 5 as the input data (such as rainfall). On the other hand, although the development of REW model including the field component (such as land cover and land use), and the model parameters distribution in the model structure is not yet accomplished, the comparison between the REW and another well established watershed hydrologic model (such as TOPLATS model applied on the same data site) will give a good idea about 10 the REW model performance.

\section{References}

Abbott, M. B., Bathurst, J. C., Cunge, J. A., O'Connell, P. E., and Rasmussen, J.: An introduction to the European Hydrological System-Systèm Hydrologic Européen, "SHE", 2: Structure of a physically-based, distributed modeling system, J. Hydrol., 87, 61-77, 1986.

15 Aitken, A. P.: Assessing systematic errors in rainfall-runoff models, J. Hydrol., 20, 121-136, 1973.

Bathurst, J. C.: Future of distributed modeling: the "Système Hydrologique Européen", J. Hydrol., 6, 265-277, 1992.

Beven, K. J.: Changing ideas in hydrology - the case of physically based models, J. Hydrol., 105, 157-172, 1989.

Brooks, R. H. and Corey, A. T.: Hydraulic properties of porous media, Colorado State University Hydrology, Fort Collins, Paper No. 3, 27 p., 1964.

De Troch, F. P.: Studie van de oppervlaktewaterhydrologie van een Oost-Vlaams stroombekken te Nederzwalm (in Dutch), Ph.D dissertation, Ghent University, Belgium, Faculty of Applied

25 Sciences, 1977.

Dunne, T.: Field studies of hillslope flow processes, in: Hillslope Hydrology, edited by: Kirkby, M. J., Wiley, Chichester, pp. 227, 1978.

Eagleson, P. S.: Climate, soil, and vegetation, 2. The distribution of annual precipitation derived from observed storm sequences, Water Resour. Res., 14, 713-721, 1978.

HESSD

3, 69-114, 2006

\section{Hydrologic responses of Zwalm catchment using the REW model}

A. El Ouazzani Taibi et al.

\section{Title Page}

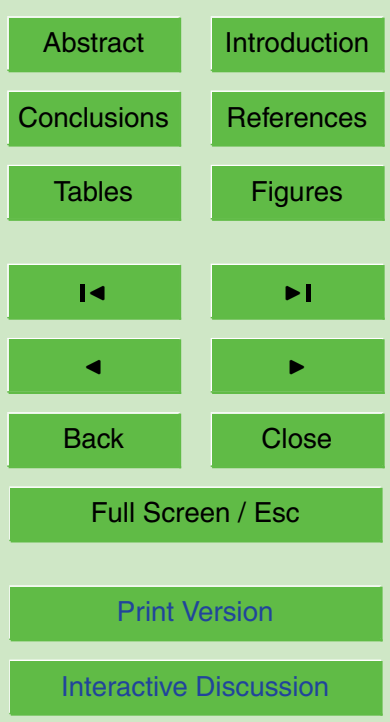

EGU 
Freeze, R. A.: Mathematical models of hillslope hydrology, in: Hillslope Hydrology, edited by: Kirkby, M. J., Chap. 6, Wiley, Chichester, 177-225, 1978.

Hassanizadeh, S. M. and Gray, W. G.: General conservation equations for multiphase systems: 1. Averaging procedure, Adv. Water Resour., 2, 131-144, 1979a.

5 Hassanizadeh, S. M. and Gray, W. G.: General conservation equations for multiphase systems: 2. Mass, momenta, energy and entropy equations, Adv. Water Resour., 2, 191-203, 1979b.

Hassanizadeh, S. M. and Gray, W. G.: Mechanics and thermodynamics of multiphase flow in porous media interphase boundaries, Adv. Water Resour., 13, 169-186, 1990.

Leopold, L. B. and Maddock, T.: The hydraulic geometry of stream channels and some physiographic implications, US. Geological Survey, Prof. Pap., 252, 9-16, 1953.

Lettenmaier, D. P. and Wood, E. F.: Hydrologic forecasting, in: Handbook of Hydrology, edited by: Maidment, D. R., McGraw-Hill, New York, 1993.

Loague, K. M. and Gander, G. A.: A-5 revisited. 1. Spatial variability of infiltration on a small rangeland catchment, Water Resour. Res., 26, 957-972, 1990.

15 Martinec, J. and Rango, A.: Merits of statistical criteria for the performance of hydrological models, Water Resour., Bulletin., 25, 421-432, 1989.

Nash, J. E. and Sutcliffe, J. V.: River flow forecasting through conceptual models, Part I-a discussion of principles, J. Hydrol., 10, 282-290, 1970.

O'Connell, P. E. and Todini, E.: Modeling of rainfall, flow and mass transport in hydrological systems: an overview, J. Hydrol., 175, 3-16, 1996.

Pauwels, V. R. N., Hoeben, R., Verhoest, N. E. C., De Troch, F. P, and Troch, P. A.: Improvement of TOPLATS-based discharge predictions through assimilation of ERS-based remotely sensed soil moisture values, J. Hydrol., 16, 995-1013, 2002.

Rawls, W. J., Brakensiek, D. L., and Saxton, K. E.: Estimation of soil water properties, Trans.

$25 \quad$ ASAE., 25, 1316-1320, 1982.

Reggiani, P. and Rientjes, T. H. M.: Flux parameterization in the Representative Elementary Watershed (REW) Approach: application to a natural basin: Water Resour. Res., 41, W04013, doi:10.1029/2004WR003693, 2005.

Reggiani, P., Sivapalan, M., and Hassanizadeh, S. M.: A unifying framework for watershed thermodynamics: Balance equations for mass, momentum, energy and entropy, and the second law of thermodynamics, Adv. Water Resour., 22, 367-398, 1998.

Reggiani, P., Hassanizadeh S. M., Sivapalan, M., and Gray, W. G.: A unifying framework for a watershed thermodynamics: constitutive relationships, Adv. Water Resour., 23, 15-39,

3, 69-114, 2006

Hydrologic responses of Zwalm catchment using the REW model

A. El Ouazzani Taibi et al.

\section{Title Page}

\section{Abstract}

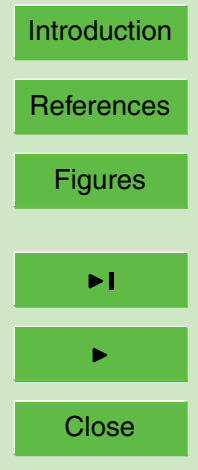

Back

Close

Full Screen / Esc

Print Version

Interactive Discussion 
1999a.

Reggiani, P., Hassanizadeh S. M., Sivapalan, M., and Gray, W. G.: Coupled equations for mass and momentum balance in a bifurcating stream channel network: Theoretical derivation and numerical implementation, Rep. ED 1266 RP, Cent. For Water Res., Univ. of West. Aust., 5 Australia, 1999b.

Reggiani, P., Sivapalan, M., and Hassanizadeh, S. M.: Conservation equations governing hillslope responses: Physical basis of water balance, Water Resour. Res., 38, 1845-1863, 2000.

Reggiani, P., Sivapalan, M., Hassanizadeh, S. M., and Gray, W. G.: Coupled equations for mass and momentum balance in a stream network: theoretical derivation and computational experiments, The Royal Society, 457, 157-189, 2001.

Shah, S. M. S., O'Connell, P. E., and Hosking, J. R. M.: Modeling the effects of spatial variability in rainfall on catchment response, 1 . Formulation and calibration of stochastic rainfall field model, J. Hydrol., 175, 67-88, 1996.

Sharma, M. L. and Luxmore, R. L.: Soil spatial variability and its consequences on simulated water balance, Water Res. Resour., 15, 1567-1573, 1979.

Sorooshian, S., Duan, Q., and Gupta, V. K.: Calibration of rainfall-runoff models: application of global optimization to the Sacramento soil moisture accounting model, Water Resour. Res., 29, 1185-1194, 1993.

20 Troch, P. A., De Troch, F. P., and Brutsaert, W.: Effective water table depth to describe initial conditions prior to storm rainfall in humid regions, Water Resour. Res., 29, 427-434, 1993.

Zhang, G., Reggiani, P., Rientjes, T. H. M., and Hassanizadeh, S. M.: Modeling rainfall-runoff relations by Representative Elementary Watershed approach, in: Proceedings of NCR-days 2002: Curent themes in Dutch river research, edited by: Leuven, R. S. E. W., van Os, A. G. and Nienhuis, P. H., NCR-publication 20-2003, Netherlands Centre River Studies, Delft, The Netherlands, 20-22, 2003.

Zhang, G. P., Fenicia, F., Rientjes, T. H. M., Reggiani, P., and Savenije, H. H. G.: Modeling runoff generation in the Geer River Basin with improved model parameterizations to the REW approach, Phys. Chem. Earth, 30, 285-296, 2005.

30 Zhang, G. P. and Savenije, H. H. G.: Rainfall-runoff modelling in a catchment with a complex groundwater flow system: application of the Representative Elementary Watershed (REW) approach, Hydrol. Earth Syst. Sci., 9, 243-261, 2005,

SRef-ID: 1607-7938/hess/2005-9-243.

\section{HESSD}

3, 69-114, 2006

Hydrologic responses of Zwalm catchment using the REW model

A. El Ouazzani Taibi et al.

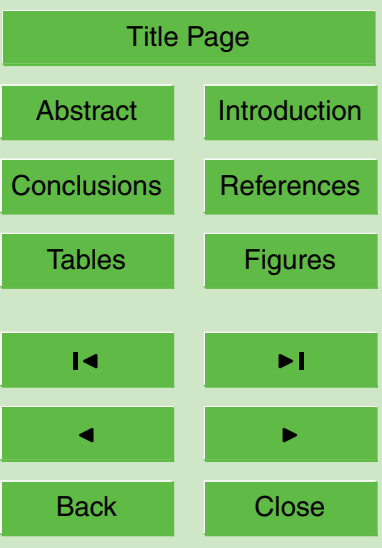

Full Screen / Esc

Print Version

Interactive Discussion 


\section{HESSD}

3, 69-114, 2006

Table 1. Statistical parameters of the REW model run with calibrated parameters on the Zwalm catchment discretized into 9 and 43 REWs.

\begin{tabular}{ccccccc}
\hline Years & \multicolumn{3}{c}{ Case 1 (9 REWs) } & \multicolumn{3}{c}{ Case 2 (43 REWs) } \\
& PBIAS $(-)$ & RMSE $\left(\mathrm{m}^{3} . \mathrm{s}^{-1}\right)$ & $\mathrm{R}(-)$ & PBIAS $(-)$ & RMSE $\left(\mathrm{m}^{3} . \mathrm{s}^{-1}\right)$ & $\mathrm{R}(-)$ \\
\hline $1994-1998$ & 8.48 & 1.836 & 0.577 & 6.57 & 1.742 & 0.569 \\
1994 & 8.58 & 2.367 & 0.434 & 7.78 & 2.125 & 0.541 \\
1995 & 6.89 & 1.725 & 0.554 & 6.18 & 1.687 & 0.759 \\
1996 & 7.79 & 2.834 & 0.533 & 7.41 & 2.111 & 0.576 \\
1997 & 15.86 & 1.649 & 0.309 & 6.71 & 1.459 & 0.314 \\
1998 & 6.21 & 1.592 & 0.445 & 4.89 & 1.585 & 0.444 \\
\hline
\end{tabular}

Hydrologic responses of Zwalm catchment using the REW model

A. El Ouazzani Taibi et al.

Title Page

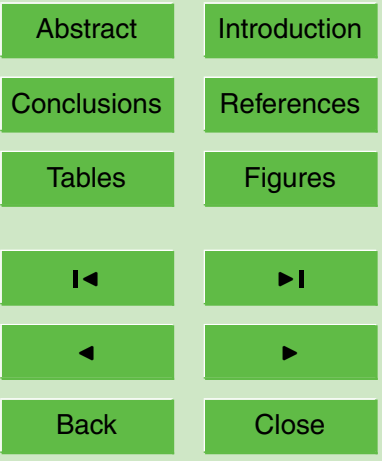

Full Screen / Esc

Print Version

Interactive Discussion 
3, 69-114, 2006

Table 2. Value intervals of saturated hydraulic conductivity (Ks) of the different soil types in Zwalm catchment according to soil texture reference curves of Rawls et al. (1982).

\begin{tabular}{cccc}
\hline Soil types & $\begin{array}{c}\text { Saturated hydraulic } \\
\text { conductivity }(\mathrm{Ks})(\mathrm{cm} / \mathrm{h})\end{array}$ & $\begin{array}{c}\mathrm{Ks} \mathrm{minimum} \\
(\mathrm{cm} / \mathrm{h})\end{array}$ & $\begin{array}{c}\text { Ks maximum } \\
(\mathrm{cm} / \mathrm{h})\end{array}$ \\
\hline Loam & 1.32 & 0.5 & 5.5 \\
Sandy loam & 2.59 & 2 & 7 \\
Clay & 0.06 & 0.01 & 0.1 \\
Sand (or heterogeneous soil) & 21 & 10 & 35 \\
\hline
\end{tabular}

Hydrologic responses of Zwalm catchment using the REW model

A. El Ouazzani Taibi et al.

Title Page

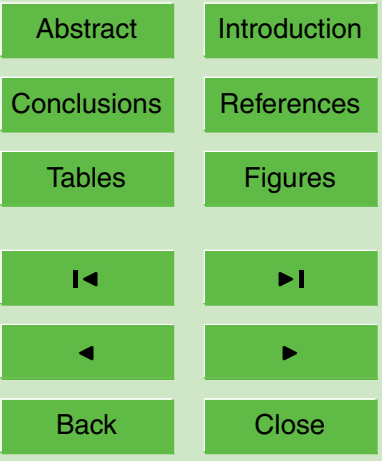

Full Screen / Esc

Print Version

Interactive Discussion 


\section{HESSD}

3, 69-114, 2006

Table 3. Statistical parameters of the comparison between observed and expected discharges obtained through the REW model run with calibrated parameters resulting from the $60 \mathrm{MC}$ realizations on 1994-1998.

\begin{tabular}{ccccccc}
\hline Years & $\begin{array}{c}\text { Mean Observed } \\
\text { discharge }\left(\mathrm{m}^{3} / \mathrm{s}\right)\end{array}$ & $\begin{array}{c}\text { Mean Sim. discharge } \\
\left(\mathrm{m}^{3} / \mathrm{s}\right)\end{array}$ & Slope & $\begin{array}{c}\text { Intercept } \\
\left(\mathrm{m}^{3} / \mathrm{s}\right)\end{array}$ & $\begin{array}{c}\mathrm{R} \\
(-)\end{array}$ & $\begin{array}{c}\text { RMSE } \\
\left(\mathrm{m}^{3} / \mathrm{s}\right)\end{array}$ \\
\hline 1994 & 1.776 & 2.236 & 0.821 & 0.776 & 0.541 & 2.215 \\
1995 & 1.651 & 2.071 & 0.939 & 0.524 & 0.759 & 1.687 \\
1996 & 1.073 & 2.387 & 0.927 & 1.383 & 0.389 & 3.156 \\
1997 & 0.961 & 2.268 & 0.767 & 1.532 & 0.347 & 2.047 \\
1998 & 1.506 & 2.554 & 0.532 & 1.752 & 0.485 & 2.156 \\
\hline
\end{tabular}

Title Page

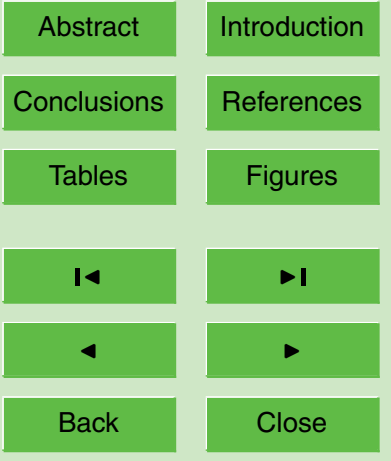

Full Screen / Esc

Print Version

Interactive Discussion 


\section{HESSD}

3, 69-114, 2006

Table 4. Statistical parameters of the comparison between observed and expected discharges obtained through the REW model run on 43 REWs under calibrated model parameter relative to limiting $K_{s}$ values.

\begin{tabular}{ccccccc}
\hline Year & \multicolumn{3}{c}{ Ks min } & \multicolumn{3}{c}{ Ks max } \\
& PBIAS & RMSE & R & PBIAS & RMSE & R \\
\hline $1994-1998$ & -14.17 & 1.827 & 0.571 & 70.72 & 0.867 & 0.463 \\
1994 & -11.17 & 1.112 & 0.541 & 61.182 & 2.233 & 0.483 \\
1995 & -12.26 & 1.503 & 0.759 & 58.56 & 2.915 & 0.579 \\
1996 & -19.18 & 2.724 & 0.533 & 87.48 & 3.541 & 0.354 \\
1997 & -14.18 & 2.788 & 0.314 & 104.81 & 3.314 & 0.337 \\
1998 & -16.05 & 1.301 & 0.444 & 61.62 & 2.233 & 0.412 \\
\hline
\end{tabular}

Title Page

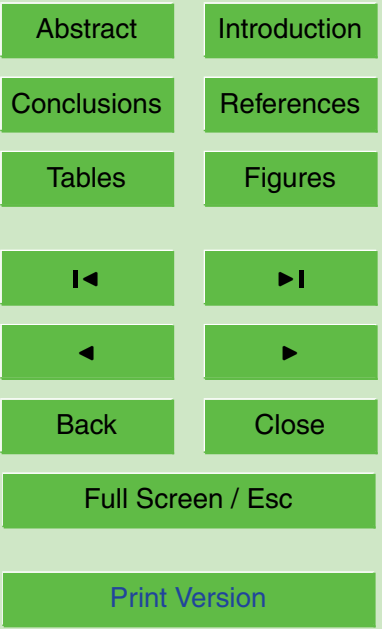

Interactive Discussion 


\section{HESSD}

3, 69-114, 2006

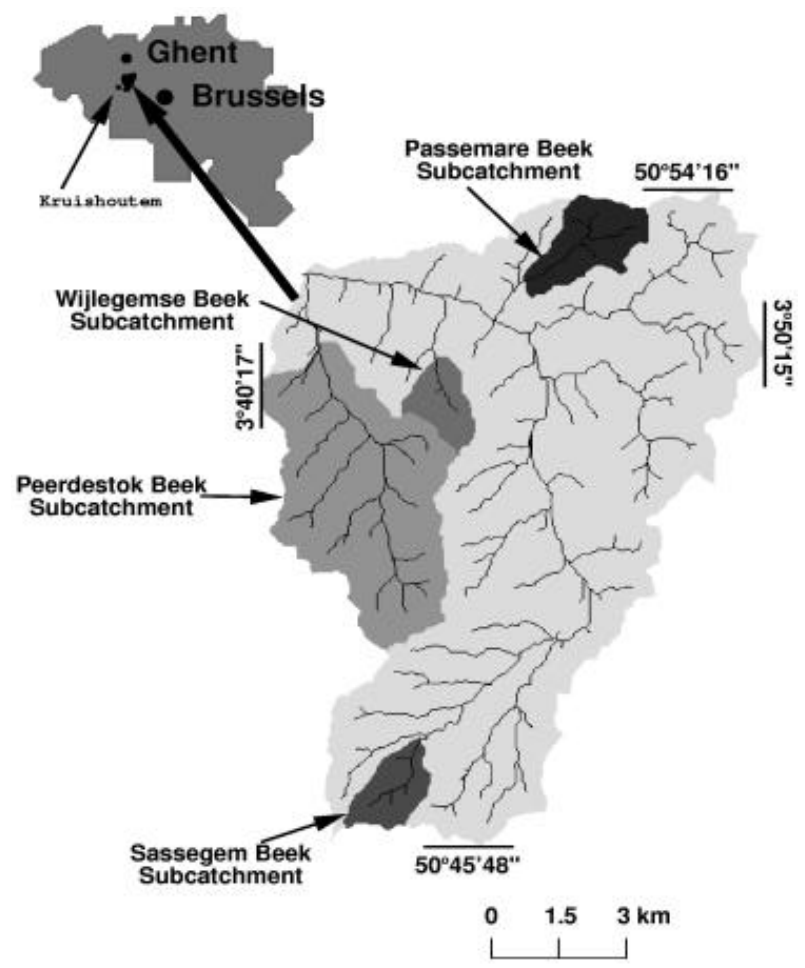

Hydrologic responses of Zwalm catchment using the REW model

A. El Ouazzani Taibi et al.

Title Page

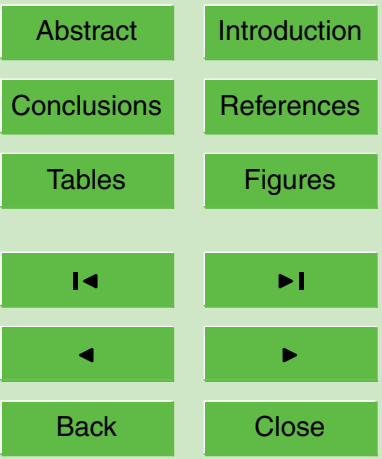

Full Screen / Esc

Print Version

Interactive Discussion 


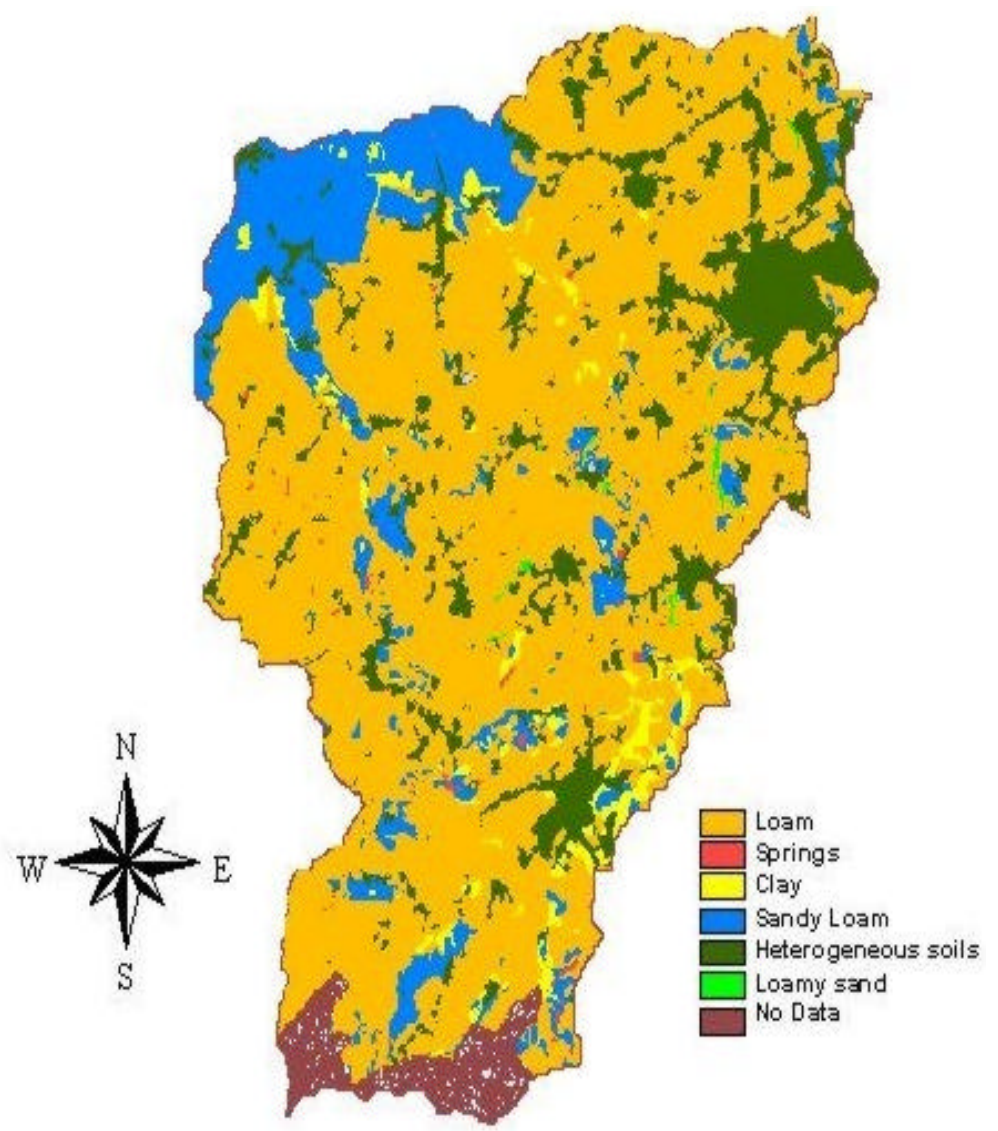

\section{HESSD}

3, 69-114, 2006

\section{Hydrologic responses of Zwalm catchment using the REW model}

A. El Ouazzani Taibi et al.

Title Page

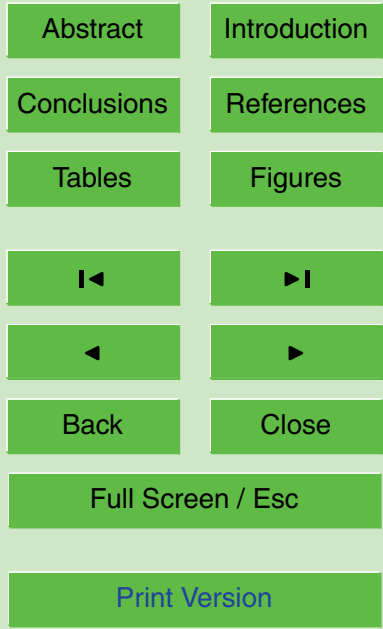

Fig. 2. Soil texture for the Zwalm catchment.

Interactive Discussion 


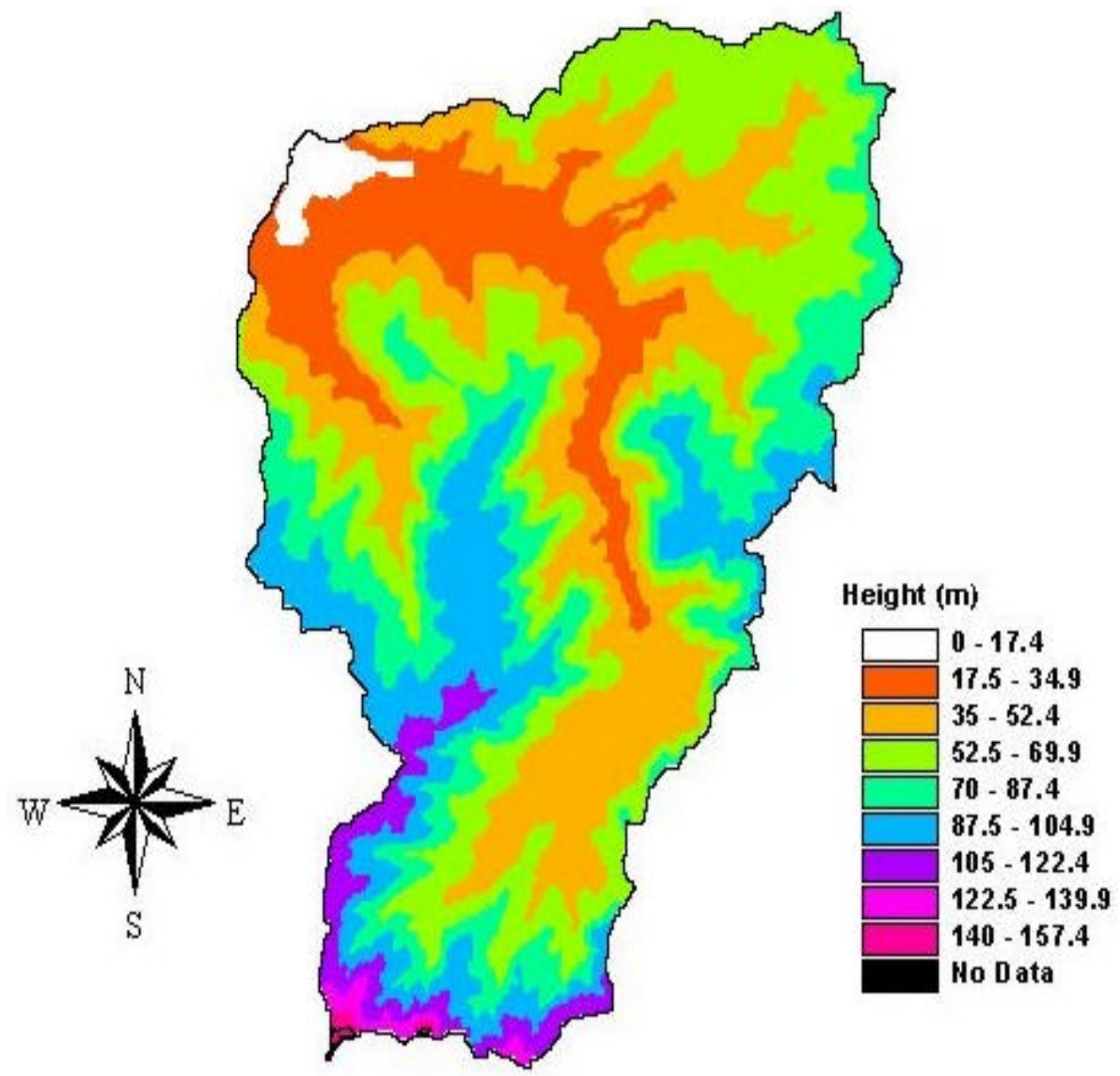

Fig. 3. Image representation of the digital elevation model of the Zwalm catchment.

\section{HESSD}

$3,69-114,2006$

\section{Hydrologic responses of Zwalm catchment using the REW model}

A. El Ouazzani Taibi et al.

Title Page

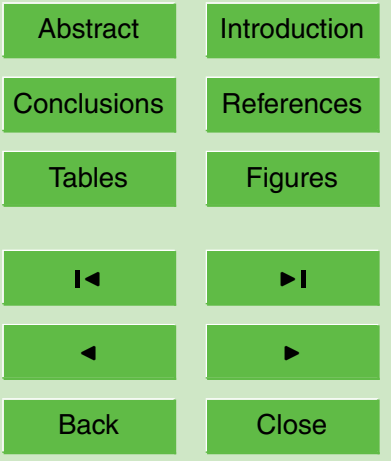

Full Screen / Esc

Print Version

Interactive Discussion 


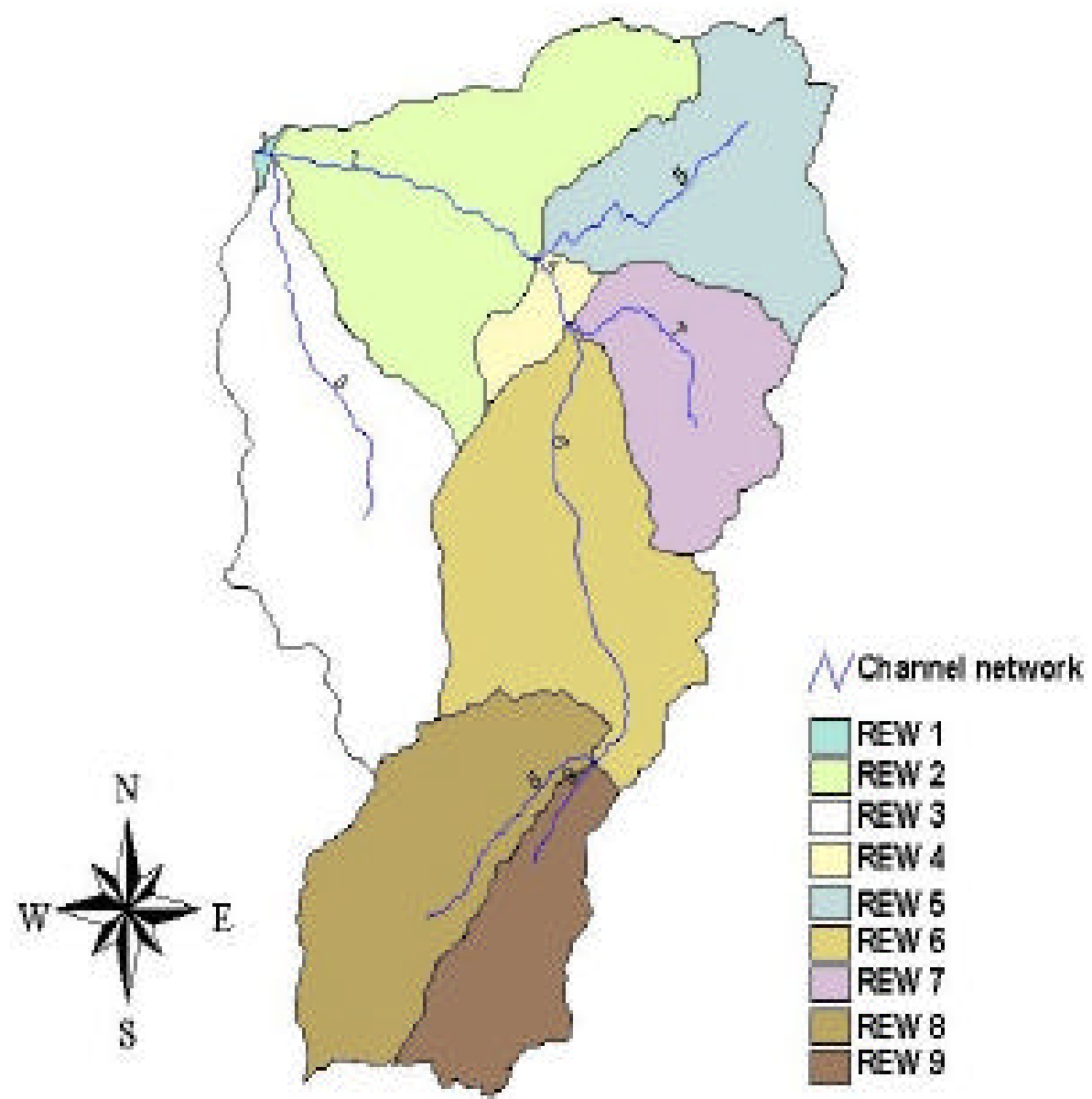

HESSD

3, 69-114, 2006

\section{Hydrologic responses of Zwalm catchment using the REW model}

A. El Ouazzani Taibi et al.

Title Page

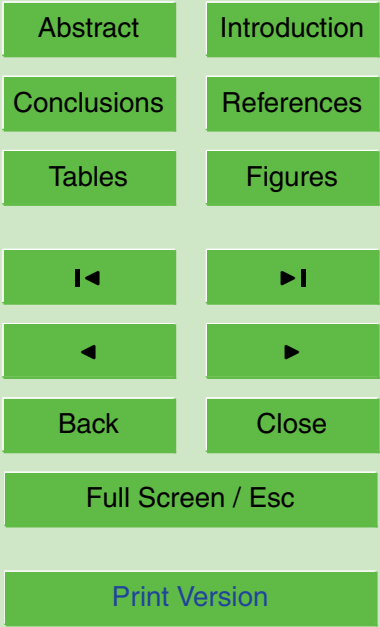

Fig. 4. Schematic representation of Zwalm catchment discretized into 9 REWs. 


\section{HESSD}

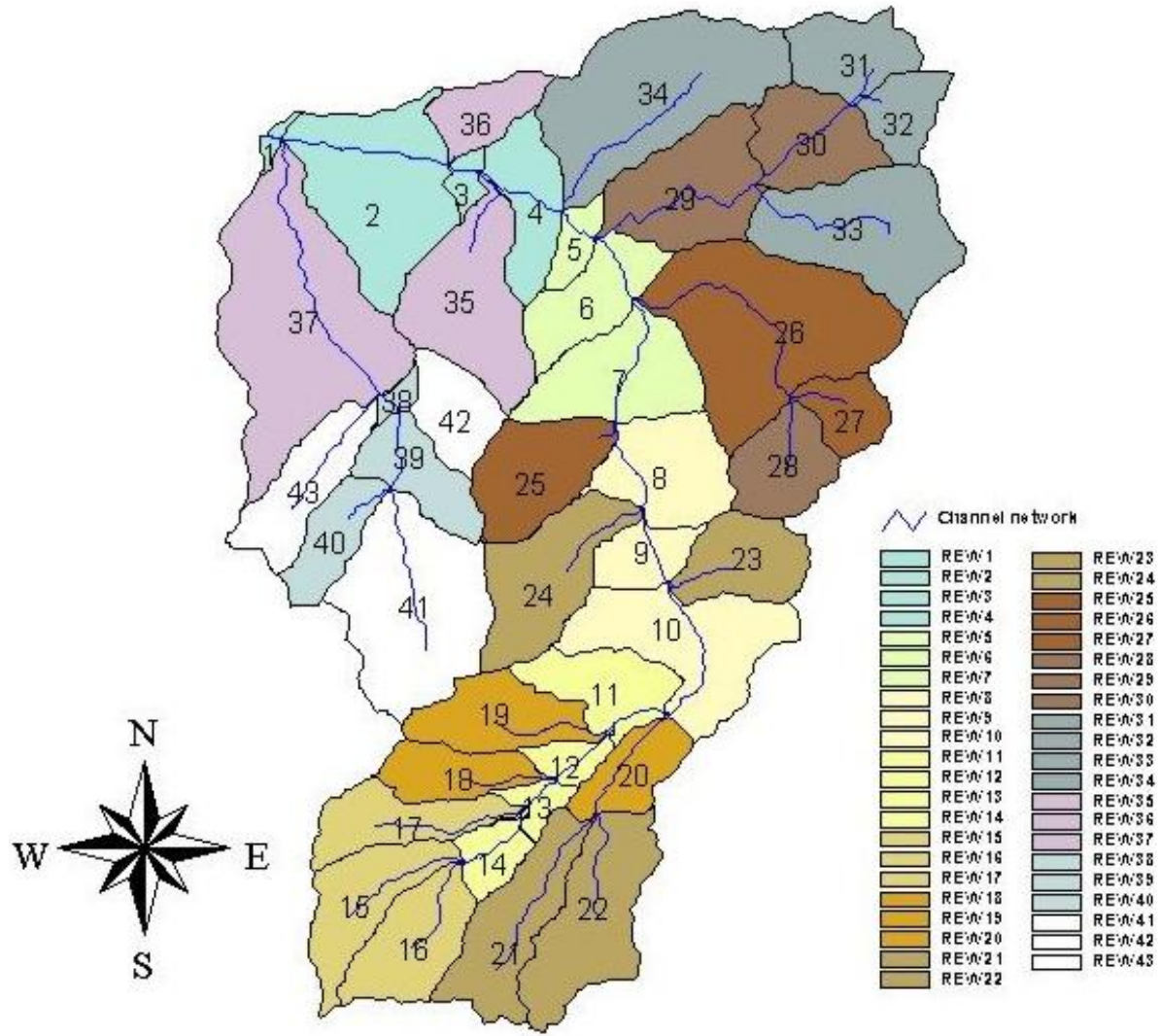

$3,69-114,2006$

\section{Hydrologic responses of Zwalm catchment using the REW model}

A. El Ouazzani Taibi et al.

Title Page

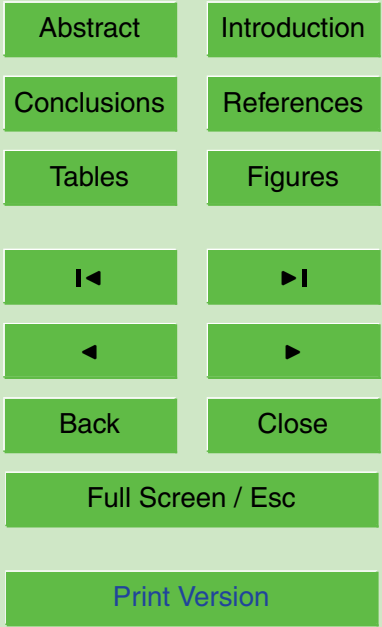

Fig. 5. Schematic representation of Zwalm catchment discretized into 43 REWs.

Interactive Discussion 


\section{HESSD}

3, 69-114, 2006

1994-1998

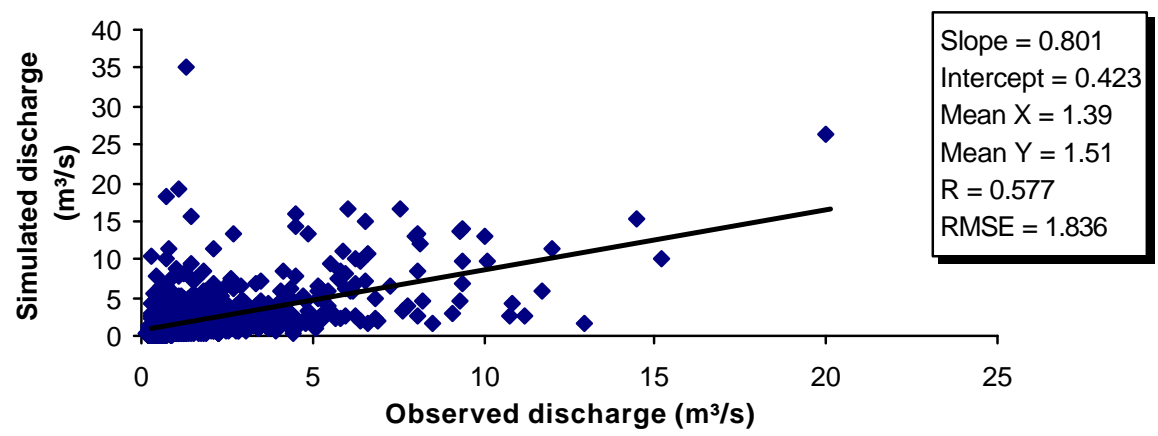

Fig. 6. Comparison between simulated and observed discharges on the Zwalm catchment discretized into 9 REWs from 1994 to 1998.

\section{Hydrologic responses of Zwalm catchment using the REW model}

A. El Ouazzani Taibi et al.

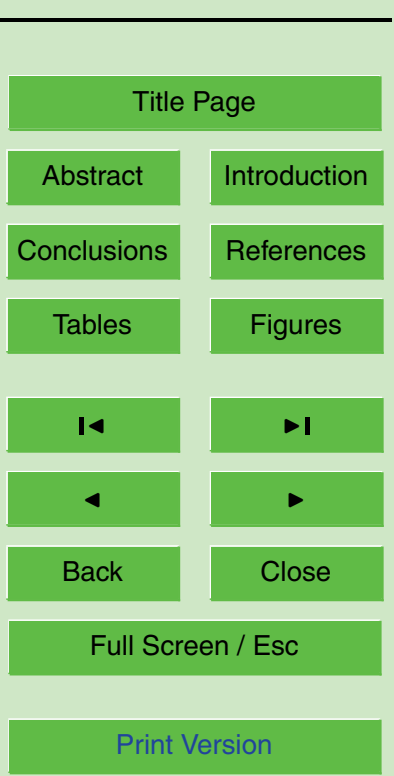

Interactive Discussion 


\section{HESSD}

3, 69-114, 2006

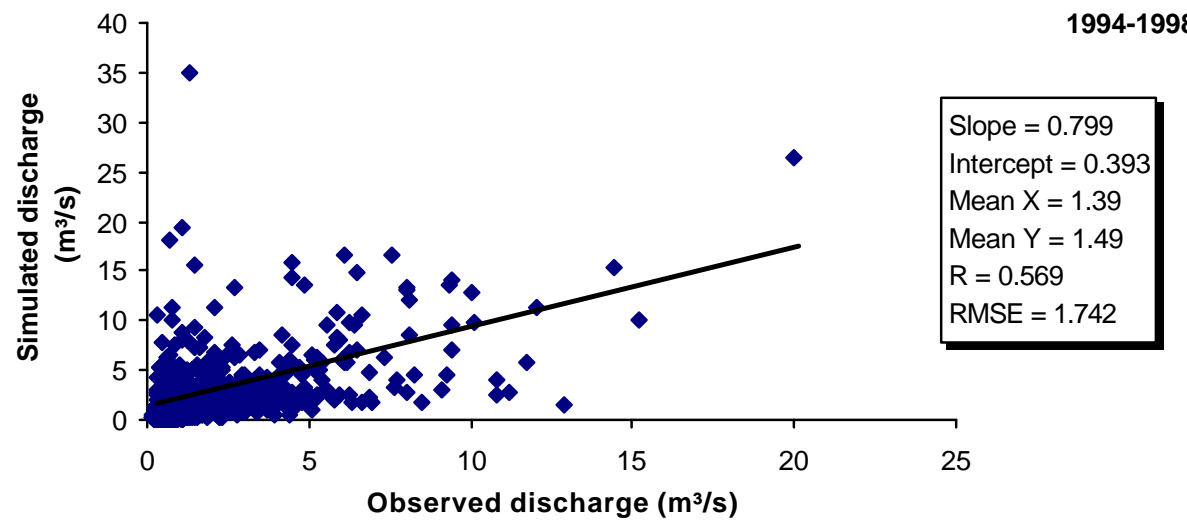

Fig. 7. Comparison between simulated and observed discharges on the Zwalm catchment discretized into 43 REWs from 1994 to 1998.

\section{Hydrologic responses of Zwalm catchment using the REW model}

A. El Ouazzani Taibi et al.

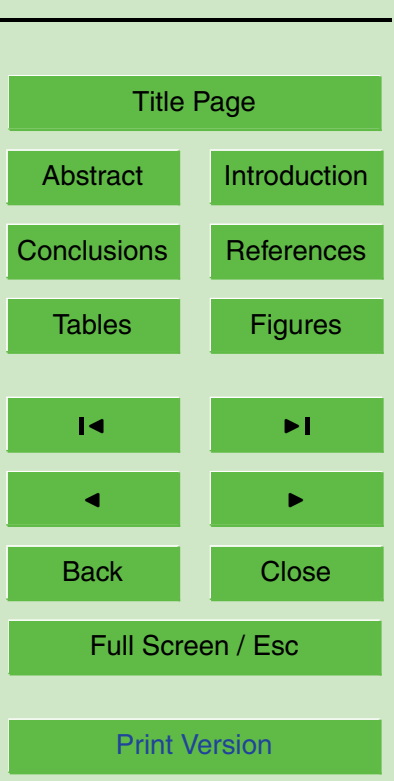

Interactive Discussion 
3, 69-114, 2006

\section{Hydrologic responses of Zwalm catchment using the REW model}

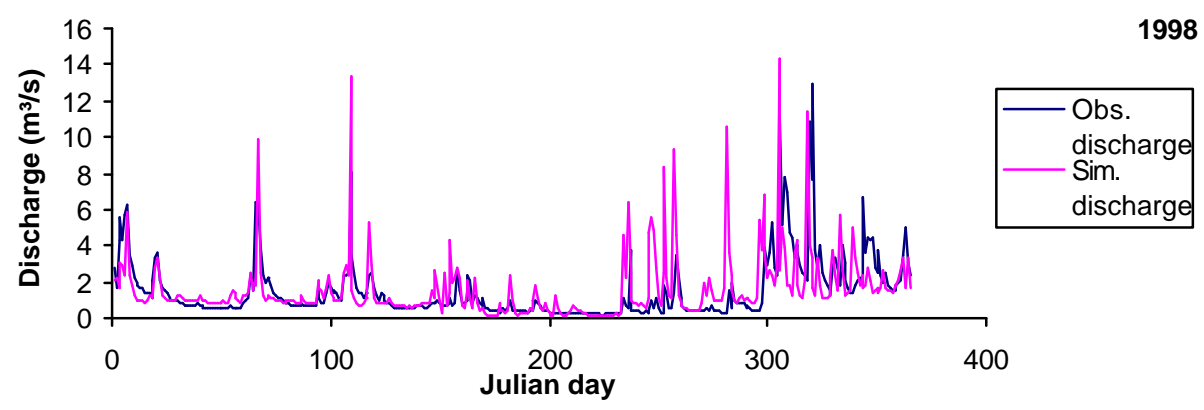

Fig. 8. Simulations versus observations of discharge hydrographs through the REW model run on the Zwalm catchment discretized into 43 REWs (data at 1998).
A. El Ouazzani Taibi et al.

\section{Title Page}

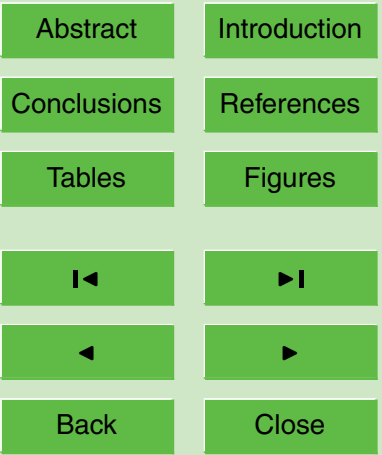

Full Screen / Esc

Print Version

Interactive Discussion 


\section{HESSD}

3, 69-114, 2006

\section{Hydrologic responses of Zwalm catchment using the REW model}

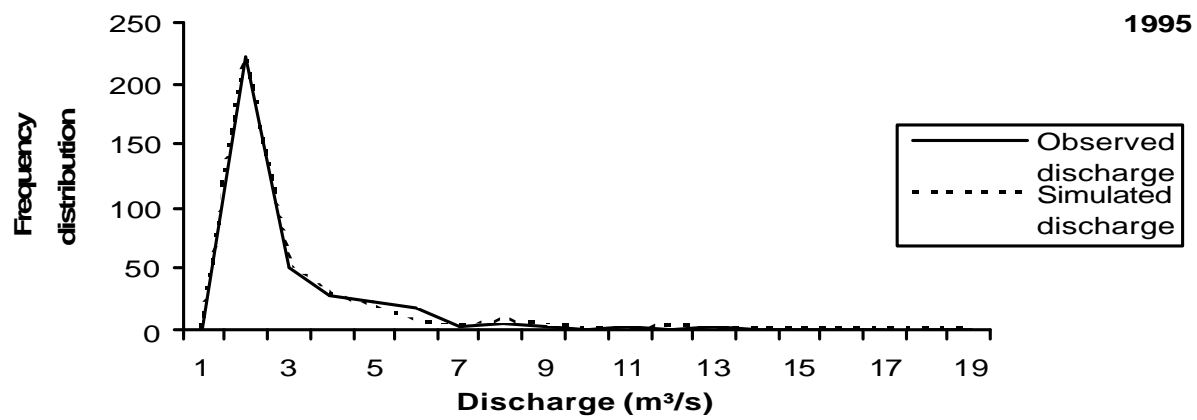

Fig. 9. Frequency distribution of observed and simulated discharges resulting from REW model run on 43 REWs for 1995.
A. El Ouazzani Taibi et al.

\section{Title Page}

\begin{tabular}{|c|c|}
\hline Abstract & Introduction \\
\hline Conclusions & References \\
\hline Tables & Figures \\
\hline
\end{tabular}

14

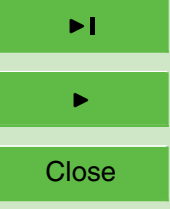

Full Screen / Esc

Print Version

Interactive Discussion 
3, 69-114, 2006

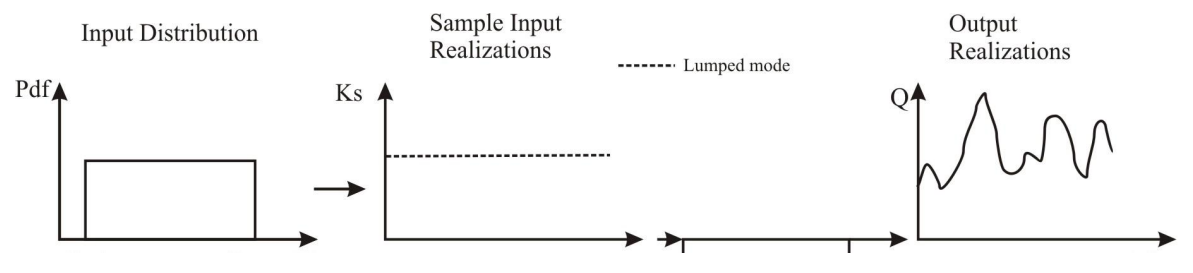

Hydrologic responses of Zwalm catchment using the REW model

A. El Ouazzani Taibi et al.

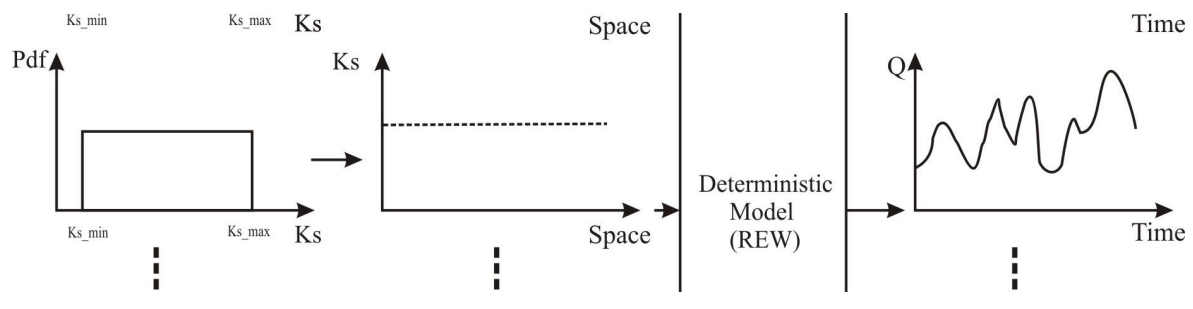

Title Page
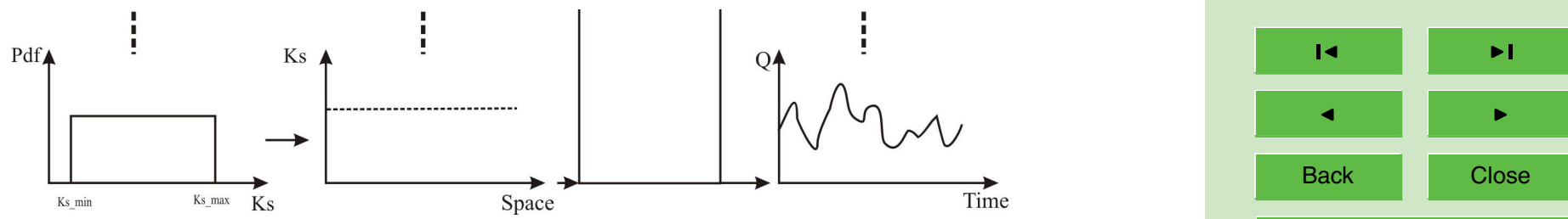

Full Screen / Esc

Fig. 10. Schematic representation of Monte-Carlo method applied on the REW model.

Print Version

Interactive Discussion 
3, 69-114, 2006

\section{Hydrologic responses of Zwalm catchment using the REW model}

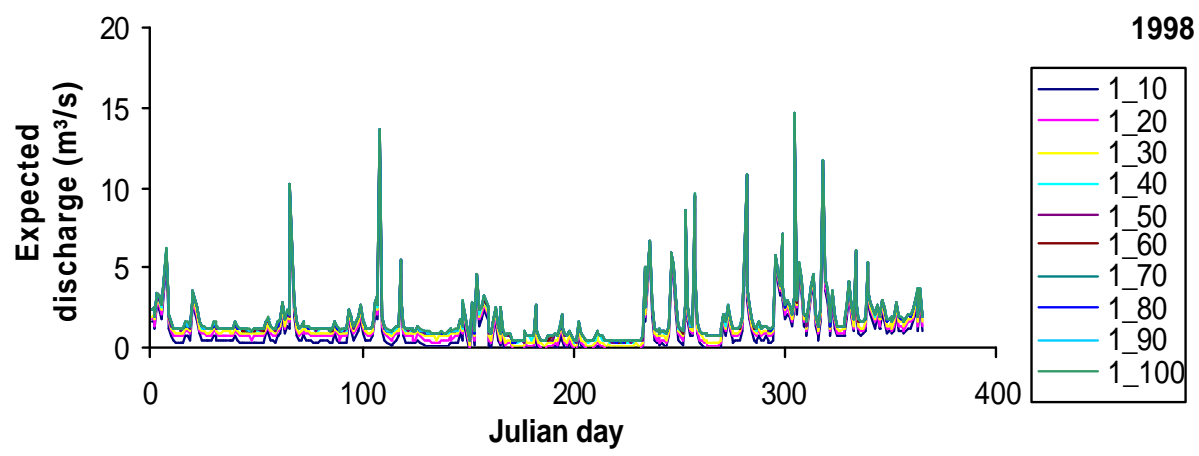

Fig. 11. Statistical convergence analysis of the expected discharge of REW model from 10 to $100 \mathrm{MC}$ realizations (data of 1998).
A. El Ouazzani Taibi et al.

Title Page

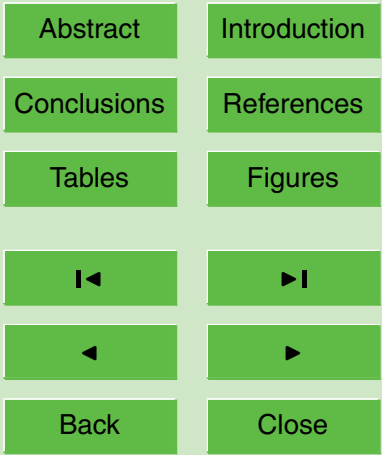

Full Screen / Esc

Print Version

Interactive Discussion 


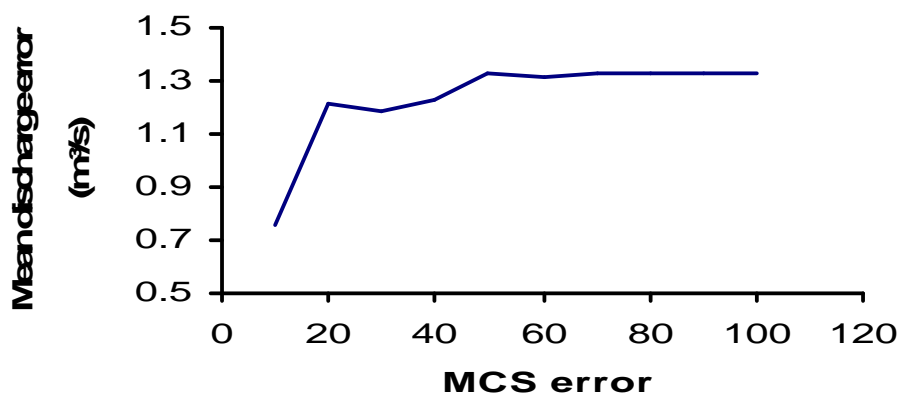

\section{HESSD}

3, 69-114, 2006

\section{Hydrologic responses of Zwalm catchment using the REW model}

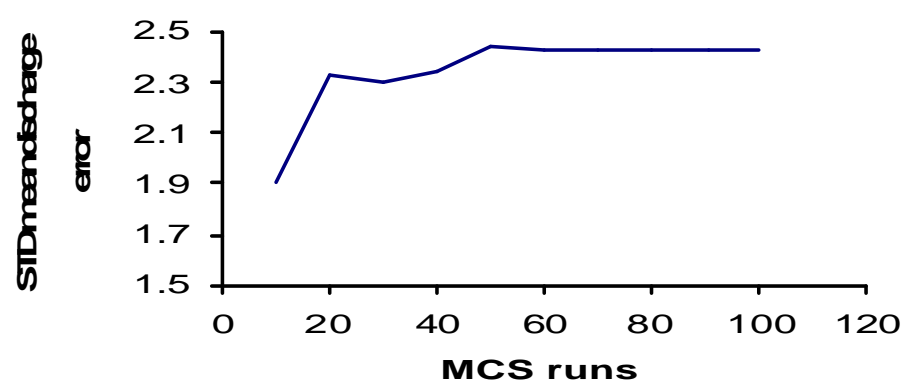

A. El Ouazzani Taibi et al.

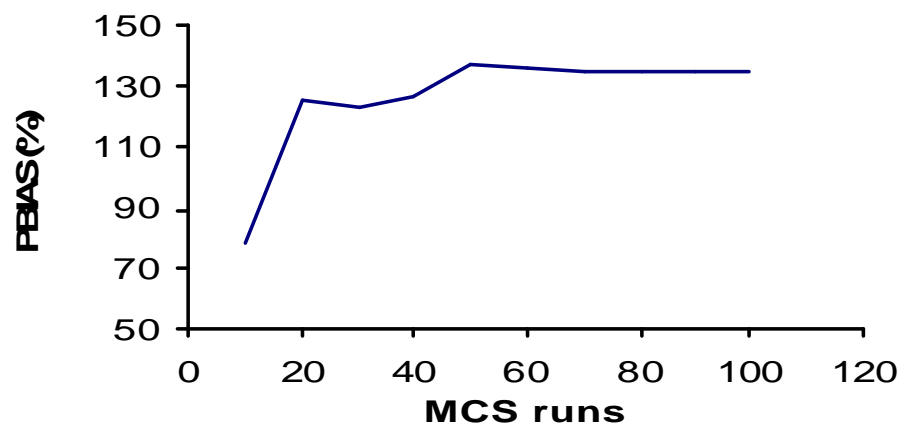

Title Page

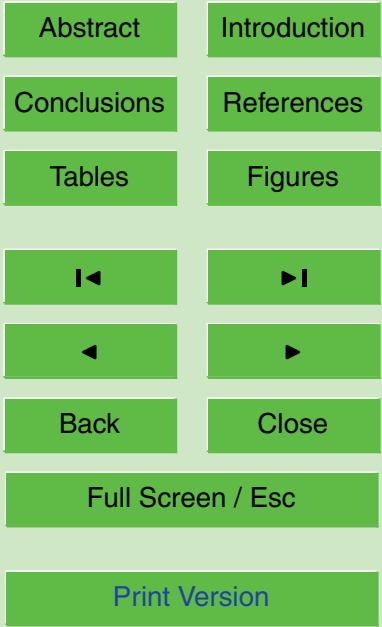

Interactive Discussion

Fig. 12. Convergence of the chosen objective functions form 10 to $100 \mathrm{MC}$ realizations. 


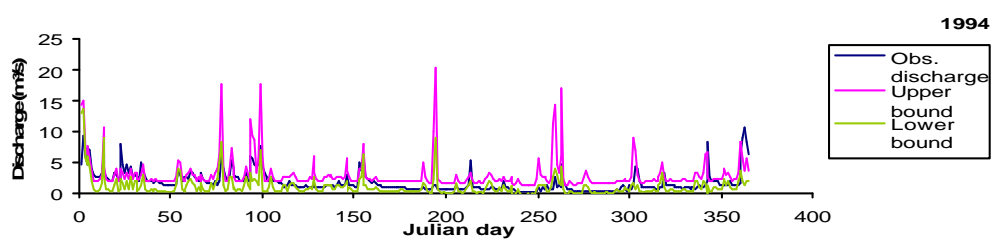

\section{HESSD}

3, 69-114, 2006

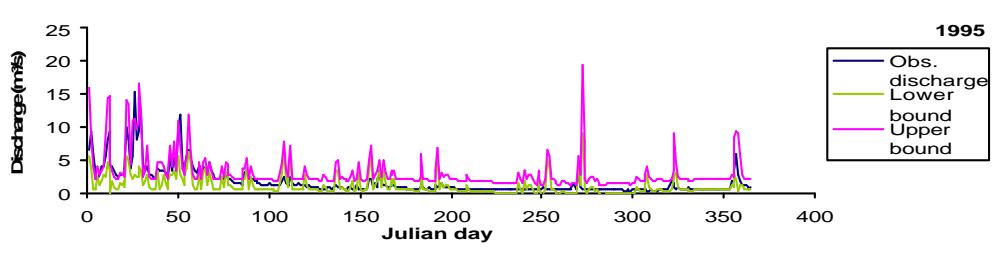

\section{Hydrologic responses of Zwalm catchment using the REW model}

A. El Ouazzani Taibi et al.

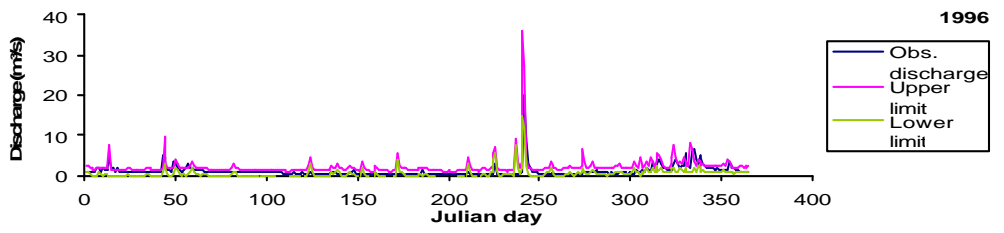

Title Page
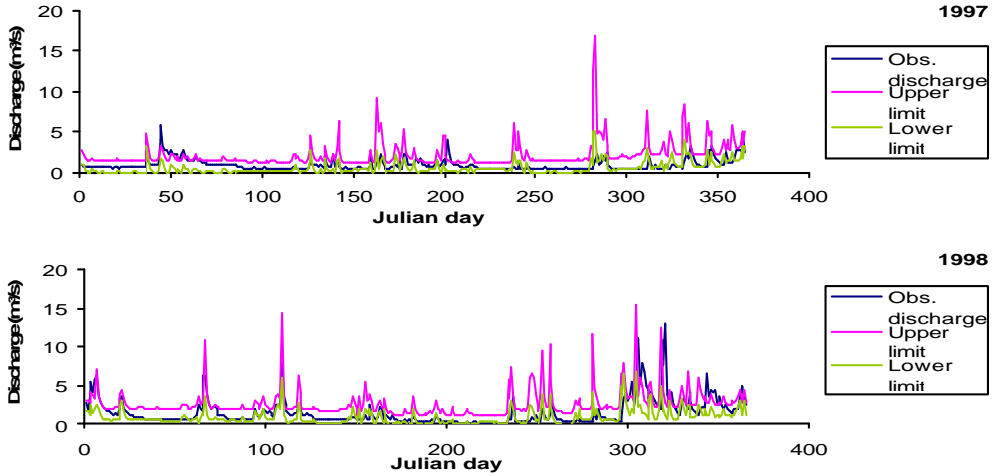

Back

Introduction

Abstract

References

Conclusions

\section{Figures}

Tables
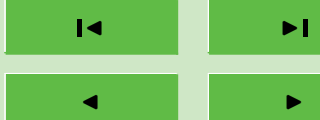

Close

Full Screen / Esc

Print Version

Fig. 13. Estimated uncertainty bounds of discharges obtained through REW model run on 43

Interactive Discussion 


\section{HESSD}

3, 69-114, 2006

\section{Hydrologic responses of Zwalm catchment using the REW model}

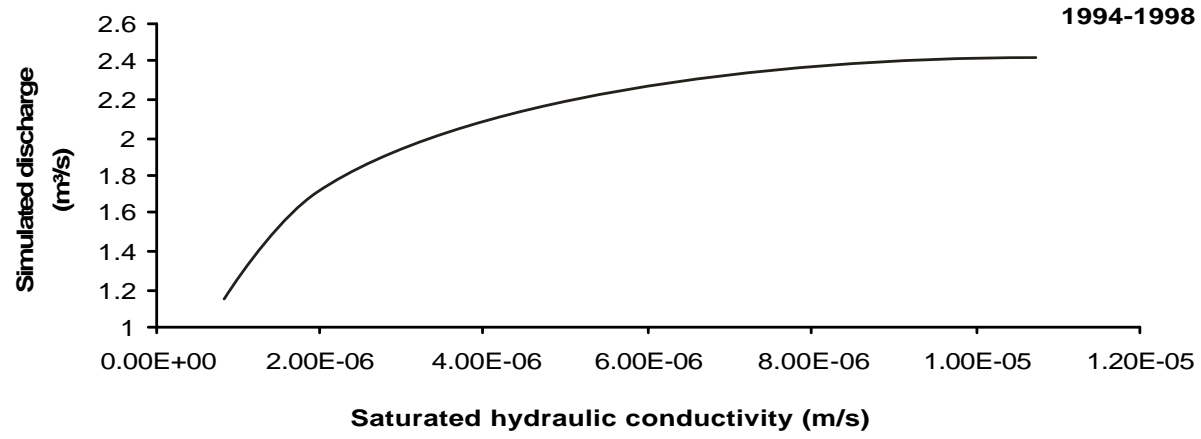

Fig. 14. Mean simulated discharge corresponding to ascending generated weighted $K_{s}$ through REW model.
A. El Ouazzani Taibi et al.

Title Page

\begin{tabular}{|c|c|}
\hline Abstract & Introduction \\
\hline Conclusions & References \\
\hline Tables & Figures \\
\hline
\end{tabular}

14

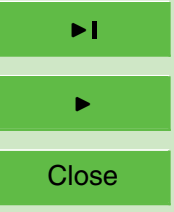

Full Screen / Esc

Print Version

Interactive Discussion 


\section{HESSD}

3, 69-114, 2006
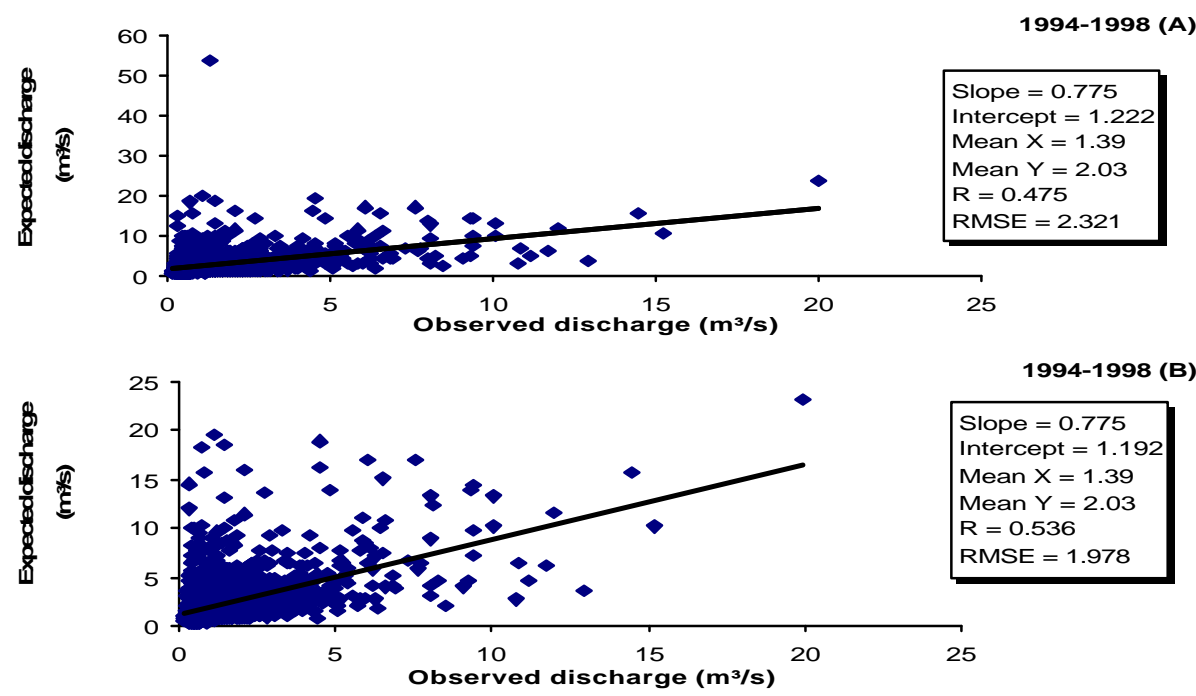

Title Page

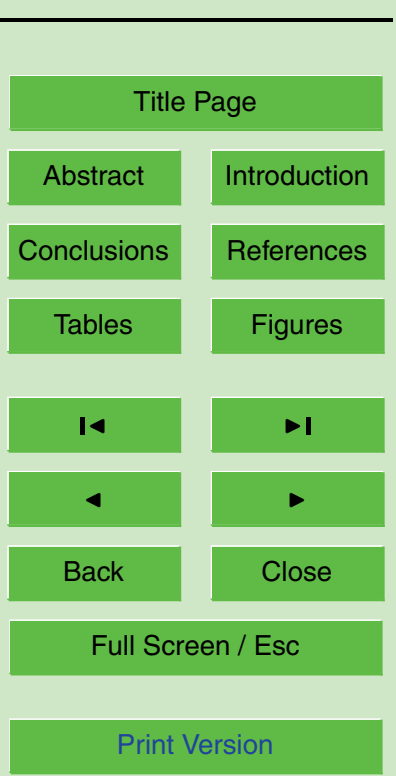

Full Screen / Esc model run from the $60 \mathrm{MC}$ realizations with erroneously $(\mathbf{A})$ and without erroneously $(\mathrm{B})$ modeled discharges on 1994-1998.

\section{Hydrologic} responses of Zwalm catchment using the REW model

A. El Ouazzani Taibi et al.

Interactive Discussion 


\section{HESSD}

3, 69-114, 2006

\section{Hydrologic responses of Zwalm catchment using the REW model}

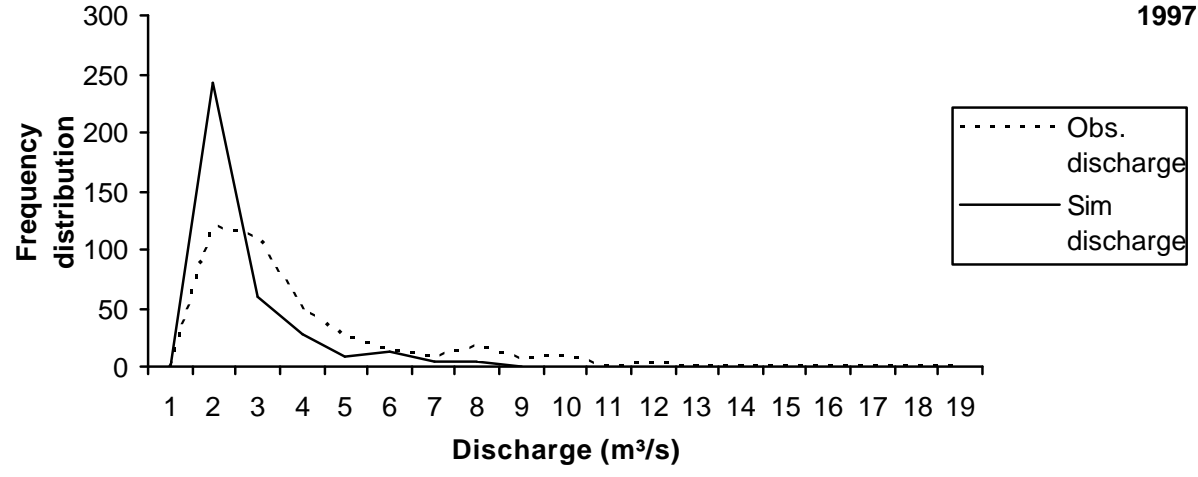

Fig. 16. Frequency distribution of observed and simulated discharges through REW model run on 43 REWs under calibrated parameters for 1997.
A. El Ouazzani Taibi et al.

\section{Title Page}

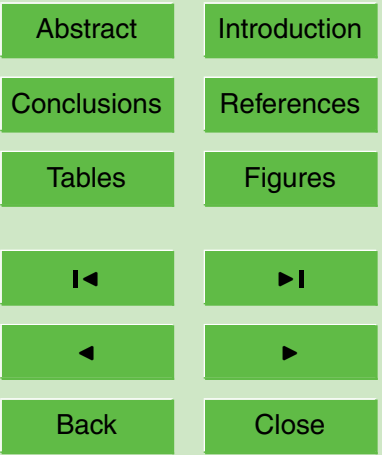

Full Screen / Esc

Print Version

Interactive Discussion 


\section{HESSD}

3, 69-114, 2006

\section{Hydrologic responses of Zwalm catchment using the REW model}

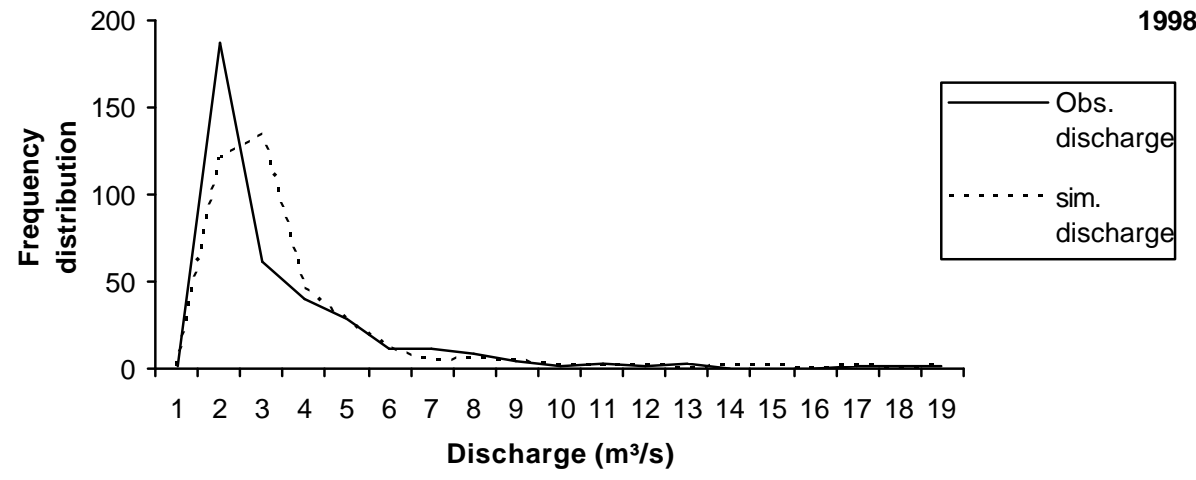

Fig. 17. Frequency distribution of observed and simulated discharges through REW model run on 43 REWs under calibrated parameters for 1998.
A. El Ouazzani Taibi et al.

\section{Title Page}

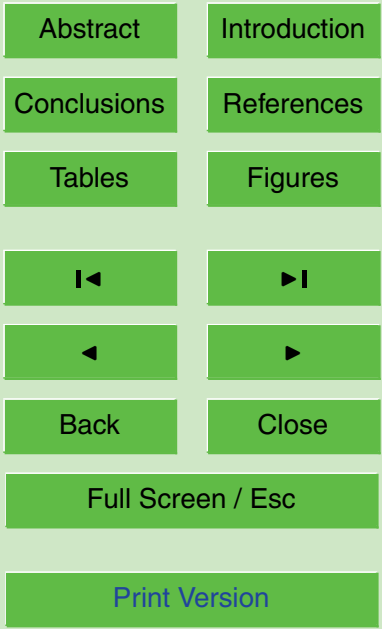

Interactive Discussion 